\title{
1 A novel protein complex that regulates active DNA demethylation \\ 2 in Arabidopsis
}

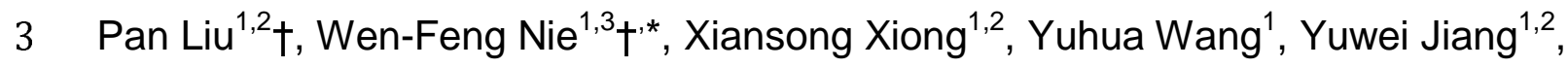

4 Pei Huang ${ }^{1,2}$, Xueqiang Lin ${ }^{1}$, Guochen Qin ${ }^{1}$, Huan Huang ${ }^{1}$, Qingfeng Niu ${ }^{1}$, Jiamu

5 Du ${ }^{1}$, Zhaobo Lang ${ }^{1}$, Rosa Lozano-Duran ${ }^{1}$, and Jian-Kang Zhu ${ }^{1,4 *}$

$7 \quad{ }^{1}$ Shanghai Center for Plant Stress Biology, Center of Excellence in Molecular

8 Plant Sciences, Chinese Academy of Sciences (CAS), Shanghai 201602, China

92 University of Chinese Academy of Sciences, No.19 (A) Yuquan Road,

10 Shijingshan District, Beijing 100049, China

113 Department of Horticulture, College of Horticulture and Plant Protection,

12 Yangzhou University, Yangzhou, Jiangsu, 225009, China

$13{ }^{4}$ Department of Horticulture \& Landscape Architecture, Purdue University, West

14 Lafayette, IN 47906, USA

15 †These authors contributed equally

16 *Correspondence: jkzhu@psc.ac.cn; wfnie@yzu.edu.cn

17 Running title: A protein complex regulates active DNA demethylation

18 Pan Liu, liupan@sibs.ac.cn

19 Wen-Feng Nie,wfnie@yzu.edu.cn

20 Xiansong Xiong, xiongxiansong@sibs.ac.cn

21 Yuhua Wang, wangyuhua@sibs.ac.cn

22 Yuwei Jiang, ywjiang@sibs.ac.cn

23 Pei Huang, peihuang@psc.ac.cn

24 Xueqiang Lin, xueqianglin@foxmail.com

25 Guochen Qin , qinguochen@sibs.ac.cn

26 Huan Huang, ahuanghuan@163.com 
27 Qingfeng Niu, qfniu@psc.ac.cn

28 Jiamu Du, dujm@sustech.edu.cn

29 Zhaobo Lang, zblang@sibs.ac.cn

30 Rosa Lozano-Duran, lozano-duran@sibs.ac.cn

31 Jian-Kang Zhu, jkzhu@sibs.ac.cn

\section{SUMMARY}

34 Active DNA demethylation is critical for altering DNA methylation patterns

35 and regulating gene expression. The 5-methylcytosine DNA

36 glycosylase/lyase ROS1 initiates a base excision repair pathway for active

37 DNA demethylation and is required for the prevention of DNA

38 hypermethylation at thousands of genomic regions in Arabidopsis. How

39 ROS1 is regulated and targeted to specific genomic regions is not well

40 understood. Here, we report the discovery of an Arabidopsis protein

41 complex that contains ROS1, regulates ROS1 gene expression, and likely

42 targets the ROS1 protein to specific genomic regions. ROS1 physically

43 interacts with a WD40 domain protein (RWD40), which in turn interacts with

44 a methyl-DNA binding protein (RMB1) as well as with a zinc finger and

45 homeobox domain protein (RHD1). RMB1 binds to DNA that is methylated in

46 any sequence context, and this binding is necessary for its function in vivo.

47 Loss-of-function mutations in RWD40, RMB1, or RHD1 cause DNA

48 hypermethylation at several tested genomic regions independently of the

49 known ROS1 regulator IDM1. Because the hypermethylated genomic

50 regions include the DNA methylation monitoring sequence in the ROS1

51 promoter, plants mutated in RWD40, RMB1, or RHD1 show increased ROS1

52 expression. Importantly, ROS1 binding to the ROS1 promoter requires

53 RWD40, RMB1, and RHD1, suggesting that this complex dictates ROS1 
54 targeting to this locus. Our results demonstrate that ROS1 forms a protein complex with RWD40, RMB1, and RHD1, and that this novel complex regulates active DNA demethylation at several endogenous loci in Arabidopsis.

60 Key words: DNA methylation, DNA demethylation, ROS1, WD40 domain,

61 methyl-DNA binding

65 DNA methylation at the fifth position of the cytosine ring is important for gene

66 regulation, transposon silencing, and imprinting in plants and many other

67 eukaryotic organisms (Robertson 2005; Slotkin and Martienssen 2007; Law and

68 Jacobsen 2010; He et al. 2011). DNA methylation occurs in different sequence

69 contexts, i.e. CG, CHG, and $\mathrm{CHH}$, where $\mathrm{H}$ represents $\mathrm{A}$, C, or T. In plants, de

70 novo DNA methylation is mediated by the RNA-directed DNA methylation (RdDM)

71 pathway, which involves small interfering RNAs (siRNAs) and scaffold RNAs in

72 addition to an array of proteins (Law and Jacobsen 2010; Zhang et al. 2018). In

73 Arabidopsis, CG methylation is maintained by DNA METHYLTRANSFERASE 1

74 (MET1) (Finnegan and Dennis 1993), while CHG methylation is maintained by the

75 plant-specific DNA methyltransferase CHROMOMETHYLASE 3 (CMT3) (Cao and

76 Jacobsen 2002). Asymmetric $\mathrm{CHH}$ methylation is maintained by DOMAIN

77 REARRANGED METHYLTRANSFERASE 2 (DRM2) through the RdDM pathway 78 and by CHROMOMETHYLASE 2 (CMT2) (Haag and Pikaard 2011; Zemach et al. 
81 Specific DNA methylation patterns are tightly regulated by DNA methylation and

82 demethylation pathways (Penterman et al. 2007; Hsieh et al. 2009; Zhu 2009;

83 Law and Jacobsen 2010; Furner and Matzke 2011; Matzke and Mosher 2014).

84 Passive DNA demethylation results from an absence of DNA methyltransferases

85 or a reduction in their activity, or from a shortage of methyl donors following DNA

86 replication (Zhang et al. 2018). In plants, active DNA demethylation is mediated

87 by 5-methylcytosine DNA glycosylases through a DNA base-excision repair

88 pathway (Choi et al. 2002; Gehring et al. 2006; Zhu et al. 2007; Zhu 2009). There

89 are four 5-methylcytosine DNA glycosylases in Arabidopsis, namely

90 REPRESSOR OF SILENCING 1 (ROS1), DEMETER (DME), DEMETER-LIKE 2

91 (DML2), and DEMETER-LIKE 3 (DML3) (Choi et al. 2002; Gong et al. 2002;

92 Penterman et al. 2007; Hsieh et al. 2009). Because the 5-methylcytosine DNA

93 glycosylases can recognize and directly remove the 5-mC base, they are critical

94 enzymes in the active DNA demethylation pathway and are thus often referred to

95 as DNA demethylases (Zhang et al. 2018). Research on how these DNA

96 demethylases are regulated and recruited to their target loci is required to reveal

97 how distinct genomic DNA methylation patterns are generated and modified

98 during organismal development and in response to environmental change.

100 The histone acetyltransferase Increased DNA Methylation 1 (IDM1) is part of the

101 IDM protein complex, which specifically recognizes certain methylated genomic

102 regions through the Methyl-CpG-Binding domain (MBD) of its subunits

103 Methyl-CpG-Binding protein MBD7 and IDM1, and through the DNA-binding

104 domain of HARBINGER TRANSPOSON-DERIVED PROTEIN HDP2 (Qian et al. 
105 2012; Qian et al. 2014; Lang et al. 2015; Duan et al. 2017). Recent research

106 showed that ROS1 physically interacts with the histone variant H2A.Z and is

107 recruited to some genomic regions via SWR1-mediated H2A.Z deposition, which

108 involves specific histone acetylation marks created by the IDM complex (Nie et al.

109 2019). Because this mechanism only applies to a subset of target genomic

110 regions of ROS1, there must be alternative mechanisms for the targeting of

111 ROS1.

112

113 In this study, we found that ROS1 forms a protein complex with RWD40, RMB1,

114 and RHD1, which are proteins that contain WD40, methyl-DNA binding, and

115 homeodomain and zinc finger domains, respectively. We show that this novel

116 protein complex, which we call the RWD40 complex, is required for the prevention

117 of DNA hypermethylation at several genomic regions in Arabidopsis, and that this

118 function is independent of the IDM-SWR1-H2A.Z pathway. One of these regions

119 is the ROS1 promoter, which contains a DNA methylation monitoring sequence

120 (MEMS) important for DNA methylation homeostasis in Arabidopsis (Lei et al.

121 2015; Williams et al. 2015). Consistent with its role in controlling the DNA

122 methylation of the ROS1 promoter, we found that this protein complex negatively

123 regulates the expression of ROS1; importantly, ROS1 binding to the MEMS

124 requires $\mathrm{RWD40,}$ RMB1, and $\mathrm{RHD1}$, suggesting that the RWD40 complex

125 dictates ROS1 targeting to this locus. Moreover, our results indicate that this

126 complex plays a role in anti-bacterial resistance, consistent with the known

127 function of ROS1 in plant-bacteria interactions. Taken together, our results

128 suggest that RWD40, RMB1, and RHD1 act in concert with ROS1 to control

129 genomic DNA methylation by regulating ROS1 gene expression and likely by

130 dictating the targeting of the ROS1 protein to selected target regions. 


\section{RESULTS}

134 A WD40 protein physically interacts with ROS1 and functions in DNA

135 demethylation

136 To date, two proteins, H2A.Z and MET18 (homolog of yeast MET18,

137 Methionine 18), have been reported to physically interact with ROS1 and to

138 regulate active DNA demethylation in Arabidopsis plants (Duan et al. 2015; Nie et

139 al. 2019). H2A.Z is required for ROS1 to target specific genomic regions defined

140 by the IDM and SWR1 protein complexes (Qian et al. 2012; Lang et al. 2015; Nie

141 et al. 2019). MET18 is a critical enzyme in the biosynthesis of the MoCo cofactor

142 required for the methyl-DNA glycosylase/lyase activity of ROS1 (Duan et al. 2015).

143 To identify additional ROS1-interacting proteins, we used yeast two-hybrid (Y2H)

144 assays to determine whether ROS1 interacts with selected proteins found in the

145 anti-FLAG pull-down products from ROS1-3xFLAG-3xHA (ros1-13 mutant

146 expressing 3xFLAG-3xHA-tagged ROS1 under its native promoter) Arabidopsis

147 plants (Lei et al. 2015) in previous experiments. The results showed that a WD40

148 domain-containing protein (which we named RWD40 for $\underline{\text { ROS1-associated WD40 }}$

149 domain-containing protein) interacts with ROS1 (Figure 1A and 1B). The

150 interaction between ROS1 and RWD40 was confirmed by bimolecular

151 fluorescence complementation (BiFC) (Figure 1C). Transient expression assays

152 in Nicotiana benthamiana leaves showed that RWD40 is mainly localized in the

153 nucleus (Figure S1A). In the anti-FLAG immunoprecipitate from

154 ROS1-3xFLAG-3xHA plants (Lei et al. 2015), but not from Col-0 control plants, we

155 identified multiple RWD40 peptides (Figure 1D). Furthermore, we also identified

156 peptides corresponding to ROS1 in the anti-FLAG immunoprecipitate from 
157 transgenic plants expressing a 3xFLAG-RWD40 fusion driven by the RWD40

158 native promoter in the rwd40-1 mutant background (Figures1D and S1B-S1D).

159 These results strongly suggest that ROS1 physically interacts with RWD40 in

160 Arabidopsis.

161 To investigate whether RWD40 regulates ROS1-dependent active DNA

162 demethylation, we used Chop-PCR to determine the DNA methylation level at the

163 AT5G39160 locus in $r w d 40-1$ and $r w d 40-2$ mutant seedlings. Similar to ros1

164 mutant plants (Qian et al. 2012), rwd40-1 and rwd40-2 plants showed increased

165 DNA methylation at the 5' region of AT5G39160 (Figure S1E). Individual locus

166 bisulfite sequencing confirmed that the DNA methylation levels at the AT5G39160

167 locus were higher in rwd40-1, rwd40-2, and ros 1-4 mutant plants than in the

168 wild-type control (Figure S1F). Interestingly, the methylation level at AT5G39160

169 was not increased in the idm1-2 mutant (Figure S1E and S1F). The expression of

$170 R W D 40-3 x F L A G$ fusion driven from its native promoter in the rwd40-1 mutant

171 reduced the methylation level at this locus (Figure S1E). These results show that

172 RWD40 interacts with ROS1 and functions in regulating DNA demethylation.

174 RMB1 and RHD1 interact with RWD40 and function in DNA demethylation

175 We noticed that the anti-FLAG immunoprecipitates from 3xFLAG-RWD40

176 transgenic plants contained peptides corresponding to AT1G63240 and

177 AT5G42780, in addition to peptides from RWD40 and ROS1 (Figure 1D).

178 AT1G63240 and AT5G42780 peptides were also detected in the anti-FLAG

179 immunoprecipitates from ROS1-3xFLAG-3xHA transgenic plants (Figure 1D). The

180 AT1G63240 protein is predicted to have a non-canonical methyl-DNA binding

181 domain, a CBD domain, and a domain of unknown function, and is hereafter

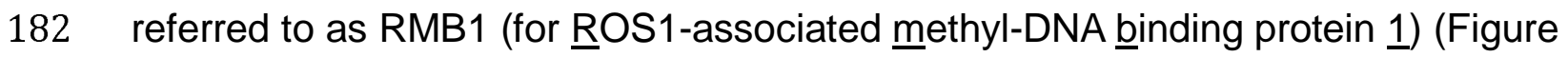


183 S2A). The AT5G42780 protein contains a zinc-finger domain and a homeodomain,

184 and is hereafter referred to as RHD1 (for $\underline{R} O S 1$-associated homeodomain protein

185 1) (Figure S2B). In Y2H assays, RWD40 interacts with RMB1 and RHD1, and

186 RMB1 interacts with RHD1 (Figure 2A). These interactions as well as the

187 interaction between RWD40 and ROS1 were confirmed by split luciferase and

188 BiFC assays in N. benthamiana leaves (Figures 2B and S2C). The assays also

189 show that neither RMB1 nor RHD1 can directly interact with ROS1 (Figures 2A,

190 2B and S2C).

191

192 RMB1 was immunoprecipitated from transgenic plants expressing a

$1933 x F L A G-R M B D 1$ fusion driven by the RMB1 native promoter in the rmb1-1 mutant

194 background (Figure S2A). The immunoprecipitate contained not only RMB1 but

195 also RWD40, RHD1, and ROS1 (Figure 1D). Similarly, the RHD1

196 immunoprecipitate from transgenic plants expressing a 3xFLAG-RHD1 fusion

197 driven by the RHD1 native promoter in the rhd1-1 background (Figure S2B)

198 contained not only RHD1 but also RMB1, ROS1, and RWD40 (Figure 1D). These

199 results show that RWD40, RMB1, and RHD1 proteins are associated with ROS1

200 in vivo.

201

202 Dysfunction of $R M B 1$ caused DNA hypermethylation at the AT5G39160 locus

203 (Figures S2D and S2E). The DNA hypermethylation phenotype of the rmb1-1

204 mutant was suppressed in transgenic plants expressing 3xFLAG-RMB1 (Figure

205 S2D). The rhd1-1 mutant, however, did not show a DNA hypermethylation

206 phenotype at the AT5G39160 locus (Figure S2F). We assessed the methylation

207 levels at another endogenous ROS1 target, AT4G18380, by Chop-PCR. Similar to

208 ros 1-4 mutant plants, rhd1-1 mutant plants had increased DNA methylation at 
209 AT4G18380 (Figure S2F). Expression of the 3xFLAG-RHD1 transgene

210 suppressed this hypermethylation phenotype of the rhd1-1 mutant (Figure S2F).

211 These results suggest that RMB1 and RHD1 function in regulating locus-specific

212 demethylation in Arabidopsis.

213

214 RWD40, RMB1, RHD1, and ROS1 form a protein complex

215 The interactions of RWD40 with ROS1, RMB1, and RHD1, and between RMB1

216 and $\mathrm{RHD} 1$ in $\mathrm{Y} 2 \mathrm{H}, \mathrm{BiFC}$, and split luciferase assays, together with their in vivo

217 association as indicated by immunoprecipitation-mass spectrometry analyses,

218 suggested that the four proteins may form a protein complex in plant cells. To

219 assess this possibility, we carried out gel filtration assays with protein extracts

220 from 3xFLAG-RMB1, 3xFLAG-RWD40, 3xFLAG-RHD1, and

221 ROS1-3xFLAG-3xHA transgenic plants. The results showed that RMB1, RWD40,

222 RHD1, and ROS1 were eluted in the same fractions, and indicated that they exist

223 in a complex with an estimated size of approximately $350 \mathrm{kDa}$ (Figure $3 \mathrm{~A}$ ). This is

224 close to the predicted total size of $328 \mathrm{kDa}$ if the four proteins are in a 1:1:1:1 ratio.

225 We co-expressed full-length RWD40, RMB1, and RHD1, and a truncated ROS1

226 protein (amino acid residues 1 to 100) in Sf9 insect cells using baculovirus vectors.

227 After conducting histidine affinity purification and gel filtration, we found that the

228 four proteins were eluted in a single peak fraction (Figure 3B). All the gel bands

229 (Figure 3B) were extracted and their identities were confirmed by mass

230 spectrometry (Table S1). Taken together, these results suggest that RWD40,

231 RMB1, RHD1, and ROS1 form a protein complex in vivo, referred to as the

232 RWD40 complex hereafter.

233

234 Identification of the protein domains that mediate the interactions within the 


\section{5 protein complex}

236 ROS1 contains an HhH-GPD domain, an End-III domain, a CXXC domain, an

237 RRM_DME domain, and an N-terminal domain of unknown function (Figure S3A).

238 The ROS1 N-terminal region (amino acid residues 41 to 100) has sequence

239 similarity to the EAR (Ethylene response factor-associated Amphiphilic

240 Repression) motif (Yang et al. 2018) (Figure S3A), and is thus referred to as the

241 ELD (EEAR-like Domain) domain. To determine which domain in ROS1 may

242 mediate the interaction between ROS1 and RWD40, we performed $\mathrm{Y} 2 \mathrm{H}$ assays

243 with various deletion mutants of ROS1. We found that the $\mathrm{N}$-terminal half (amino

244 acid residues 1 to 696) of ROS1 interacts with RWD40, whereas the C-terminal

245 half (amino acid residues 697 to 1393) does not (Figure S3B). Further truncation

246 of the N-terminal half of ROS1 showed that the ELD domain (amino acid residues

24741 to 100 ) is sufficient to mediate the interaction with RWD40 (Figure S3B).

249 We also performed $\mathrm{Y} 2 \mathrm{H}$ assays with various deletion mutants of RWD40, and

250 found that the N-terminal half of RWD40, including two LISH-CTLH domains but

251 not the WD40 domain, is sufficient to enable the interaction with ROS1 (Figures

252 1B and S3B). On the other hand, the WD40 domain of RWD40 interacts with

253 RMB1 in $\mathrm{Y} 2 \mathrm{H}$ assays (Figure 2D). The C-terminal region of RMB1 interacts with

254 the WD40 domain of RWD40 (Figures 2C and 2D), and is thus referred to as the

255 WID (WD40 interaction domain) domain (Figure 2C). The WD40 domain of

256 RWD40 is also capable of mediating the interaction between RWD40 and RHD1

257 (Figures S3C and S3D). The zinc-finger domain of RHD1 is responsible for the

258 interaction with RWD40, while both the zinc finger domain and homeodomain of

259 RHD1 are necessary for the interaction with RMB1 (Figures S3C and S3E). In the

$260 \mathrm{Y} 2 \mathrm{H}$ assay, RHD1 also interacts with itself, and this self-interaction is mediated 
261 through the zinc finger domain (Figures S3C and S3D).

262

263 RMB1 binds to methylated DNA through the MBD domain

264 Arabidopsis has 13 canonical MBD proteins (Zemach and Grafi 2007). Our

265 analysis indicates that Arabidopsis also has three non-canonical MBD proteins,

266 namely RMB1, IDM1, and the protein encoded by AT4G14920 (Figure S4A). The

267 IDM complex contains two MBD domain proteins, i.e., the histone

268 acetyltransferase IDM1 and MBD7 (Qian et al. 2012; Lang et al. 2015). The two

269 MBD domain proteins recognize methylated cytosine and thus ensure that the

270 IDM histone acetyltransferase complex is directed only to methylated sequences

271 (Qian et al. 2012; Lang et al. 2015). Many of the amino acid residues in the MBD

272 domain of RMB1 are not conserved compared to the other MBD proteins (Figure

273 S4B). We carried out electrophoretic mobility shift assays (EMSA) to determine

274 whether RMB1 can bind to methylated DNA. The EMSA assays showed that

$275 \mathrm{RMB} 1$ is capable of binding to DNA probes containing $\mathrm{CG}, \mathrm{CHG}$, or $\mathrm{CHH}$

276 methylation, and that the binding was competitively blocked by unlabeled

277 methylated DNA but to a lower extent by unmethylated DNA of the same

278 sequence (Figures $4 \mathrm{~A}$ and $4 \mathrm{~B}$ ). To confirm RMB1 binding to methylated DNA, we

279 carried out microscale thermophoresis (MST) assays and found that the MBD

280 domain of RMB1 is capable of binding to DNA methylated in any sequence

281 context (Figures 4C). We constructed four mutant versions of the MBD domain,

282 including W22G, Y38F, T49A, and K50T (Figure S4B), and found that the W22G,

283 Y38F, and T49A mutations decreased the methyl-DNA binding activity, while the

284 K50T mutation abolished the methyl-DNA binding activity (Figures 4C).

285 Expression of the wild-type but not of the K50T mutant version of RMB1 under its 286 native promoter complemented the At5g39160 DNA hypermethylation phenotype 
287 of the rmb1-1 mutant (Figure S5A). These results show that RMB1 is a novel

288 methyl-DNA-binding protein, and that its methyl-DNA binding is critical for it to

289 function in active DNA demethylation.

290

291 RWD40, RMB1, and RHD1 regulate ROS1 expression

292 To begin to explore the function of the protein complex formed by RWD40, RMB1,

293 RHD1, and ROS1 in plants, we assessed the DNA methylation levels at the ROS1

294 promoter region, which contains a DNA methylation monitoring sequence that

295 senses methylation and demethylation activities and that regulates ROS1

296 expression (Lei et al. 2015; Williams et al. 2015). Individual locus bisulfite

297 sequencing showed that the DNA methylation level at the MEMS was increased in

298 rwd40-1, rmb1-1, rhd1-1, and ros1-4 compared to the wild-type control (Figure

$2995 A)$. In contrast, the MEMS DNA methylation level was not increased in the

300 idm1-2 mutant (Figure 5A). Consistent with the changes in DNA methylation

301 levels at the MEMS, ROS1 expression was increased in $r w d 40, r m b 1$, and $r h d 1$

302 mutant plants but not in idm1-2 mutant plants (Figure 5B). In the ros 1-4 mutant,

303 ROS1 expression measured using the 5' primer pair (Figure 5B) was also

304 increased, as expected (Lei et al.,2015). The expression of the 3xFLAG-RWD40

305 transgene driven by the $R W D 40$ native promoter in the $r w d 40-1$ mutant restored

306 the expression of ROS1 to the wild-type level (Figure 5B). ChIP-qPCR assays

307 confirmed that ROS1, RWD40, RMB1, and RHD1 were enriched at the MEMS in

308 the ROS1 promoter (Figure 5C), and that RWD40, RMB1, and RHD1 were

309 necessary for ROS1 binding to the MEMS region (Figure 5D). Taken together,

310 these results indicate that $R W D 40, R M B 1$, and $R H D 1$ mediate binding of ROS1 to

311 the MEMS region, hence regulating its methylation level and the subsequent

312 expression of ROS1. 
314 RWD40, RMB1, and RHD1 regulate DNA demethylation in an

315 IDM1-independent manner

316 RWD40, RMB1, RHD1, and ROS1, but not IDM1, are necessary for the

317 prevention of DNA hypermethylation at the MEMS in the ROS1 promoter (Figure

318 5A). These results suggest that RWD40, RMB1, and RHD1 might regulate

319 ROS1-mediated DNA demethylation in a manner independent of IDM1. To further

320 investigate the role of RWD40, RMB1, and RHD1 in the regulation of active DNA

321 demethylation, we used Chop-PCR to assess the DNA methylation levels in

322 rwd40-1, rmb1-1, and rhd1-1 single mutants and in the $r w d 40$ rmb1 rhd1 triple

323 mutant, as well as in idm1-2, at several genomic targets of ROS1. Similar to DNA

324 methylation levels in the ros 1-4 mutant, DNA methylation levels at the

325 AT1G35140, AT4G00660, AT4G18380, and AT5G55875 loci were increased in

$326 r w d 40-1, r m b 1-1$, and rhd1-1, but not idm1-2 mutant plants, relative to the Col-0

327 control (Figure 5E). Individual locus bisulfite sequencing data confirmed that the

328 DNA methylation levels at these ROS1 targets were increased in rwd40-1,

329 rmb1-1, rhd1-1, and ros 1-4 mutant plants, but not in idm1-2 mutant plants (Figure

$3305 \mathrm{~F}$ ). Analysis of the rwd40 rmb1 rhd1 triple mutant indicated that the rwd40-1,

331 rmb1-1, and rhd1-1 mutations are not additive in causing the DNA

332 hypermethylation phenotype (Figures 5F). We also determined the DNA

333 methylation levels at several genomic regions (including DT-75, DT-76, DT-77,

334 and DT-78) that are known to be hypermethylated in idm1 and ros 1 mutants (Qian

335 et al. 2012)and that are amenable to Chop-PCR assays (Duan et al. 2017). DNA

336 methylation levels were not increased at these regions in $r w d 40-1, r m b 1-1$, or

337 rhd1-1 mutant plants (Figure S6A). Together, these results support the inference

338 that RWD40, RMB1, and RHD1 function in regulating active DNA demethylation 
339 independently of IDM1.

341 ROS1 and the IDM complex are required for the prevention of silencing of the

342 35S:SUC2 reporter gene in Arabidopsis (Qian et al. 2014; Lang et al. 2015; Duan

343 et al. 2017; Nie et al. 2019). When we introgressed the 35S:SUC2 reporter gene

344 into $r w d 40-1, r m b 1-1$, or rhd1-1 mutant plants through genetic crosses, we found

345 that the reporter gene was not silenced in any of these mutants (Figures S6B and

346 S6C). Therefore, unlike IDM1 or ROS1, RWD40, RMB1, and RHD1 are not

347 required for the prevention of silencing of the 35S:SUC2 reporter gene in

348 Arabidopsis. We examined the deposition of H2A.Z and H3K18ac in wild-type

349 35S:SUC2 plants (Nie et al., 2019) at the 5 loci shown in Figure 5F, where DNA

350 methylation levels were increased in RW40 complex-related mutants, but not in

351 idm1-2 (Figures 5E and 5F). Unlike the moderate co-existence of H2A.Z and

352 H3K18ac in the IDM1-dependent AT1G62760 locus, only at the AT4G18380 locus

353 were H2A.Z and H3K18ac both less deposited; at the AT5G55875 locus, H2A.Z

354 and H3K18ac were rarely deposited; either H2A.Z or H3K18ac was deposited at

355 the MEMS, AT1G35140, and AT4G00660 loci (Figure S6D). No consistent change

356 in histone acetylation or H2A.Z deposition could be found at these 5 selected loci,

357 which is in line with the notion that RWD40, RMB1, and RHD1 function in an

358 IDM1-independent manner.

360 The RWD40 complex prevents the silencing of several endogenous genes

361 and regulates antibacterial resistance

362 To test the effect of the dysfunction of the RWD40 complex on genome-wide

363 transcript levels, we profiled the transcriptomes of ros $1-4$ and $r w d 40$ rmb1 rhd1

364 mutant plants by mRNA-seq. There were 3,817 and 2,970 up-regulated genes 
365 and 4,028 and 2,918 down-regulated genes in rwd40 rmbd1 rhd1 triple-mutant

366 and ros 1-4 mutant plants, respectively, compared to wild-type Col-0 plants (Figure

$3676 \mathrm{~A}$ and Table S2). Of these, 1,673 up-regulated and 1,941 down-regulated genes

368 were shared between rwd40 rmbd1 rhd1 and ros1-4 (Figure 6B). Several

369 commonly down-regulated DEGs in rwd40 rmbd1 rhd1 and ros 1-4 mutants were

370 confirmed by qRT-PCR (Figure 6C). These results suggest that the RWD40

371 complex is required for the expression of some endogenous genes.

373 Exposure to the bacterial pathogen Pseudomonas syringae pv. tomato DC3000

374 (Pto DC3000) causes moderate but widespread differential DNA methylation in

375 Arabidopsis (Dowen et al. 2012). A mildly enhanced bacterial growth was

376 observed in ros 1 plants treated with the bacterial pathogen Pto DC3000,

377 supporting a role of ROS1-dependent DNA demethylation in antibacterial

378 resistance (Yu et al. 2013). To test whether the RWD40 complex regulates

379 antibacterial resistance, we first inoculated the RWD40 complex mutants with Pto

380 DC3000 by flood-inoculation assays (Ishiga et al. 2011). We found that similar to

381 ros 1-4 mutant plants, rwd40-1, rmb1-1, and rhd1-1 mutant plants were more

382 susceptible to Pto DC3000 than wild-type plants (Figures 6D and 6E). These

383 results point at a biological relevance of the RWD40 DNA demethylation complex

384 in Arabidopsis antibacterial defense.

\section{DISCUSSION}

387 In this study, we identified RWD40, RMB1, and RHD1 as cellular factors critical

388 for the regulation of ROS1 expression and for the prevention of DNA

389 hypermethylation at several endogenous genomic regions (Figure 5). DNA

390 methylation patterns are important for organismal development, carcinogenesis, 
391 and many other diseases, as well as for human aging (Jung and Pfeifer 2015;

392 Klutstein et al. 2016). It is therefore important to understand how DNA methylation

393 patterns are controlled by active DNA demethylation (Penterman et al. 2007;

394 Furner and Matzke 2011; Zhang et al. 2018). Although the biochemistry of

395 ROS1-mediated enzymatic removal of DNA methylation has been extensively

396 studied, the mechanisms by which the enzymatic machinery is regulated and

397 recruited to specific target sites are poorly understood (Qian et al. 2012; Lang et

398 al. 2015; Nie et al. 2019). Our results indicate that RWD40, RMB1, RHD1, and

399 ROS1 form a RWD40 complex, and that this protein complex contributes to

400 locus-specific DNA demethylation. Moreover, ROS1 binding to the ROS1

401 promoter requires RWD40, RMB1, and RHD1, suggesting that the RWD40

402 complex directs ROS1 targeting to this locus to regulate the expression of ROS1.

403 Thus, the activity of the RWD40 complex at target genomic loci is likely

404 self-restrained by ROS1 expression level through its demethylation function at the

405 MEMS site on the ROS1 gene promoter (Figure 7). These findings provide novel

406 insights into the regulation and targeting of active DNA demethylation in plants.

407 In mammals, active DNA demethylation is initiated by the Tet dioxygenases (Wu

408 and Zhang 2017). Several transcription factors have been shown to interact with

409 and to target Tet enzymes to genes critical for cell differentiation and

410 reprogramming (Costa et al. 2013; de la Rica et al. 2013; Wang et al. 2015; Xiong

411 et al. 2016; Sardina et al. 2018). In Arabidopsis, the IDM histone acetyltransferase

412 complex is required for directing ROS1 to a subset of active DNA demethylation

413 target regions (Qian et al. 2012; Qian et al. 2014; Lang et al. 2015; Duan et al.

414 2017; Nie et al. 2019). MBD7 in the IDM complex recognizes dense mCpG sites

415 and thus ensures that ROS1 is eventually targeted to genomic regions with

416 densely methylated CpG sequences (Lang et al. 2015). On the other hand, the 
417 SANT/Myb/trihelix DNA-binding motif-containing protein HDP2 in the IDM

418 complex probably helps direct the complex to possible regulatory sequences, thus

419 avoiding heavily methylated transposon body regions and some genic regions

420 that should not be demethylated (Duan et al. 2017). The IDM complex creates

421 histone acetylation marks that attract the SWR complex, which then deposits the

422 histone variant H2A.Z. Once deposited at the targeted site, H2A.Z helps to recruit

423 ROS1 through a direct physical interaction (Nie et al. 2019). The protein complex

424 identified in this study is similar to the IDM complex in that it also contains a

425 protein (i.e., RMB1) that recognizes methylated DNA, and a transcription

426 factor-like protein (i.e., RHD1). RMB1 ensures that the complex is directed to

427 methylated genomic regions, while RHD1 probably helps to target the complex to

428 regulatory sequences. Like the IDM complex, the RWD40 protein complex is likely

429 also important for targeting active DNA demethylation to specific genomic regions

430 (Figures 5A, 5E, and 5F). Our results suggest that the RWD40 complex targets

431 active DNA demethylation to genomic regions that are different from those

432 targeted by the IDM complex. This difference can be explained by the fact that

$433 \mathrm{RMB1}$ recognizes $\mathrm{mC}$ marks in all sequence contexts (Figure 4), whereas MBD7

434 and IDM1 bind to mCpG sequences only (Qian et al. 2012; Lang et al. 2015)

435 (Figure S5B and S5C). In addition, HDP2 and RHD1 likely have different

436 sequence specificities in their interactions with DNA, which probably also

437 contributes to the different targeting preferences of the two protein complexes.

438 The lack of DNA hypermethylation at the AT5G39160 locus in rhd1 mutant plants

439 (Figure S2F) indicates that RHD1 may be dispensable for some targets of the

440 RWD40 protein complex, either due to genetic redundancy with another

441 transcription factor-like protein, or because its function is genomic

442 region-dependent. It should be noted that H2A.Z deposition and histone 
443 acetylation are not restricted to the IDM1-dependent ROS1-targets, since H2A.Z

444 or H3K18ac are also deposited at some loci targeted by RWD40 complex (Figure

445 S6D); this observation suggests that other IDM1-independent acetylation

446 mechanisms are associated with ROS1 activity and possibly involved in H2A.Z

447 deposition.

449 Another important difference between the RWD40 complex and the IDM complex

450 is that the RWD40 complex contains ROS1 and thus has a direct role in targeting

451 active DNA demethylation. Furthermore, because the RWD40 complex targets the

452 MEMS in the ROS1 promoter, it can regulate ROS1 gene expression. We propose

453 that through the regulation of ROS1 gene expression, the RWD40 complex is

454 expected to have a broad effect on genomic DNA methylation patterns. The

455 genome-wide effects of DNA demethylation factors can be difficult to analyze

456 because DNA methylation changes caused by mutations in these factors are often

457 quite subtle (Nie et al. 2019). Future studies are needed to determine the

458 genome-wide effects of $r w d 40, r m b 1$, and $r h d 1$ mutations, and to identify the

459 direct targets of the RWD40 complex at the whole genome level.

461 The data presented here, together with our previous work (Lang et al. 2015; Nie et

462 al. 2019), suggest that active DNA demethylation activities are targeted only to

463 methylated genomic regions by proteins that bind to methyl-DNA. Such targeting

464 would be biologically relevant, because only methylated genomic regions may

465 require demethylation. Our findings also suggest that the presence of a

466 transcription factor-like protein is important for the targeting of active DNA

467 demethylation. It is tempting to speculate that these transcription factor-like

468 proteins preferentially bind to regulatory sequences, and thus help target active 
469 DNA demethylation to regulatory sequences in order to prevent harmful silencing 470 and precisely regulate gene expression.

471

472 MATERIALS AND METHODS

\section{Plant materials and growth conditions}

474 Plants were grown under long-day conditions (16-h light/8-h dark) at $22^{\circ} \mathrm{C}$. The

475 T-DNA insertion mutants rwd40-1 (SALK_068825), rwd40-2 (SALK_012947), 476 rmb1-1 (SALK_110885), rmb1-2 (SALK_100783), rhd1-1 (SALK_092897), ros 1-4

477 (SALK_045303), and idm1-2 (SALK_062999) were obtained from the Arabidopsis 478 Biological Resource Center (http://www.arabidopsis.org) and genotyped by PCR 479 with the primers listed in Table S3.

481 METHODS DETAILS

482 Mutant plant complementation

483 For the complementation of mutants, the RWD40, RMB1, or RHD1 genomic DNA 484 with the 2-kb upstream region (as the native promoter region) was amplified from 485 genomic DNA of Col-0 with the primers listed in Table S3. The amplification 486 products were cloned into the pCambia1305 vector (with a $3 x F L A G$ tag or a $4873 \times M Y C$ tag at the C-terminus) by T4 DNA ligase (NEB). The constructs were 488 transformed into mutants using Agrobacterium tumefaciens GV3101 by the 489 standard floral dip method (Clough and Bent 1998). Unsegregated T3 490 homozygous complementation lines were then used for further experiments.

\section{Real-time qPCR and Chop-PCR}

492 For real-time qPCR analysis, total RNA was extracted from $0.1 \mathrm{~g}$ of 14-day-old 493 Arabidopsis seedlings with the RNeasy plant kit (Qiagen). $2 \mu \mathrm{g}$ of the mRNA were 494 converted into cDNA with the First-Strand cDNA Synthesis Kit (TRNSGENE Bio., 
495 China) following the manufacturer's instructions, and the cDNAs were used as

496 templates for real-time PCR with iQ SYBR green supermix (Bio-RAD). For

497 Chop-PCR, genomic DNA was extracted from 14-day-old seedlings, and 500 ng

498 of DNA were digested with the indicated methylation-sensitive enzyme in a $20-\mu \mathrm{L}$

499 reaction mixture. After digestion, PCR was performed using $2 \mu$ of the digested

500 DNA as template in a $20-\mu$ l reaction mixture with the primers listed in Table S3.

501 Undigested DNA was amplified as the loading control.

\section{IP and LC-MS/MS analysis}

503 For immunoprecipitation (IP), about $5 \mathrm{~g}$ of floral tissue for each epitope-tagged

504 transgenic line were used. Dynabeads (10004D, Invitrogen) conjugated with

505 FLAG antibody (F1804, Sigma) were applied for IP. Affinity purification was

506 performed as previously described (Law et al. 2010), and the protein samples

507 were subjected to Liquid Chromatography-Mass Spectrometry (LC-MS) /MS

508 analysis as previously described (Lang et al. 2015; Qin et al. 2017; Nie et al.

509 2019).

510 Protein extraction and western blot detection

511 About $0.1 \mathrm{~g}$ of plant tissue were harvested and ground to a fine power in liquid $\mathrm{N}_{2}$.

512 Total protein was extracted by protein lysis buffer (LB: $0.5 \mathrm{mM} \mathrm{DTT,} 5 \mathrm{mM} \mathrm{MgCl}$,

$51350 \mathrm{mM}$ Tris (pH 7.6), 10\% glycerol, $150 \mathrm{mM} \mathrm{NaCl}, 0.1 \%$ NP-40, $1 \mathrm{mM}$ PMSF, and

514 protease inhibitor cocktail (Roche)). The proteins were then detected by western

515 blot with anti-FLAG (F1804, Sigma) or anti-MYC (05-724, Millipore).

\section{Split luciferase complementation assays}

517 The coding sequences of RWD40, RMB1, RHD1, and ROS1 proteins were cloned

518 into pCAMBIA-cLUC and/or pCAMBIA-nLUC vectors. A. tumefaciens GV3101

519 carrying different constructs were infiltrated into 4-week-old $N$. benthamiana

520 leaves. Luciferase activity was detected $48 \mathrm{~h}$ post infiltration. 


\section{Individual locus bisulfite sequencing}

$522200 \mathrm{ng}$ of genomic DNA extracted from Col-0 wild type and the indicated mutants

523 were treated with the BisulFlash DNA Modification Kit (Epigentek) according to

524 the manufacturer's protocol. A 2- $\mu$ L volume of bisulfite-treated DNA was used for

525 PCR amplification with the primers listed in Table S3. The PCR products were

526 cloned into the pMD18-T vector (Takara) according to the supplier's instructions.

527 At least 15 independent clones were sequenced per sample and analyzed using

528 the online tool Kismeth (http://katahdin.mssm.edu/kismeth/revpage.pl).

\section{Bimolecular fluorescence complementation (BiFC) assay}

530 The coding sequences of RWD40, RMB1, RHD1, and ROS1 were cloned into the

531 p2YN or p2YC vector to generate fused split YFP constructs. For protein-protein

532 interaction analysis, $A$. tumefaciens GV3101 carrying the indicated constructs

533 were cultured overnight. When the cultures reached an $\mathrm{OD}_{600}$ of 1.0 , they were

534 firstly collected by centrifuge and then were resuspended in buffer containing 10

$535 \mathrm{mM} \mathrm{MgCl}_{2}, 100 \mu \mathrm{M}$ acetosyringone, and $10 \mathrm{mM} \mathrm{MES} \mathrm{(pH} \mathrm{5.6).} \mathrm{The} \mathrm{suspensions}$

536 were kept at room temperature for 2 hours and then were infiltrated into $N$.

537 benthamiana leaves. Fluorescence was examined at 2 days post infiltration.

\section{Gel filtration assays and western blot analysis}

539 Western blotting of gel filtration samples was performed as previously described

540 (Duan et al. 2017). In brief, $2 \mathrm{~g}$ of flower tissue from Col-0 wild type or from the

541 indicated transgenic plants were harvested and ground into a fine power in liquid

$542 \mathrm{~N}_{2}$. The fine powder was resuspended in $3 \mathrm{ml}$ of lysis buffer (0.5 mM DTT, $5 \mathrm{mM}$

$543 \mathrm{MgCl}_{2}, 50 \mathrm{mM}$ Tris [pH 7.6], 10\% glycerol, $150 \mathrm{mM} \mathrm{NaCl}, 0.1 \% \mathrm{NP}-40,1 \mathrm{mM}$

544 PMSF), and the suspension was kept at $4^{\circ} \mathrm{C}$ for 5 min without shaking. The

545 supernatant was loaded into a HiPrep 16/60 Sephacryl S-300 HR column (GE

546 Healthcare), and 10 fractions were collected. Each fraction was run on $10 \%$ 
547 SDS-PAGE for western blot detection.

548 Y2H assay

549 In brief, the corresponding cDNA sequences were cloned into pGADT7-AD or

550 pGBKT7-BD vectors (Clontech), and the pair of genes to be tested for interaction

551 were co-transformed into the yeast strain Gold (Clontech). Y2H assays were

552 performed as previously described (Bai et al. 2013).

\section{Protein expression and purification}

554 Arabidopsis $R W D 40, R M B 1$, and $R H D 1$ were cloned into the pFastBac1 vector

555 adding a FLAG tag at their N-terminus. Arabidopsis ROS1 (encoding amino acids

556 1-100) was cloned into the pFastBac1 vector adding a double His tag

557 (6xHis-13aa-10xHis) fused with GFP at its N-terminus. Recombinant

558 baculoviruses were generated by the Bac-to-Bac system in Sf9 insect cells. For

559 protein co-expression, the insect cells were grown to a density of $2.0 \mathrm{E}+06$ cells

560 per $\mathrm{mL}$ and were then infected with four separate viruses. The infected cells were

561 cultured for $60-72 \square \mathrm{h}$ at $27^{\circ} \mathrm{C}$ before collection. Collected cell pellets were stored

562 at $-80^{\circ} \mathrm{C}$ before use. Each cell pellet was resuspended in buffer A (20 mM HEPES

$563 \mathrm{pH} 7.5,150 \mathrm{mM} \mathrm{NaCl}, 10 \%$ v/v glycerol, $50 \mathrm{mM}$ imidazole, and $0.1 \mathrm{mM}$ Tris

564 (2-carboxyethyl) phosphine hydrochloride (TCEP), supplemented with protease

565 inhibitor cocktail) and then lysed by sonication. The suspension was centrifuged

566 at $18,000 \times g$ for $30 \mathrm{~min}$ at $4^{\circ} \mathrm{C}$. The supernatant was incubated with Ni-NTA resin

567 at $4^{\circ} \mathrm{C}$ for $1 \mathrm{~h}$. The resin was washed with 20 column volumes of buffer $\mathrm{A}$ in a

568 gravity column. The complex was eluted by buffer B (buffer A with 250 mM

569 imidazole) and was then loaded onto a Superdex200 10/300 GL column

570 equilibrated with buffer containing $20 \mathrm{mM}$ HEPES pH 7.5, $100 \mathrm{mM} \mathrm{NaCl}$, and 0.1

$571 \mathrm{mM}$ TCEP. Fractions containing the ROS1 complex were collected and analyzed

572 with SDS-PAGE and Coomassie brilliant blue staining. 


\section{Microscale thermophoresis (MST)}

574 The sequence encoding the MBD domain of RMB1 (amino acids 1-81) was

575 cloned into a pET-Sumo vector to fuse the target protein with a hexahistidine plus

576 yeast sumo tag at the N-terminus. The His-Sumo tagged MBD domain of RMB1

577 recombinant protein was transformed into Escherichia coli strain BL21 (DE3).

578 When the $\mathrm{OD}_{600}$ of the cell culture reached 0.7 , IPTG was added to a final

579 concentration of $0.2 \mathrm{mM}$ to induce protein expression. The cells were harvested

580 by centrifugation, re-suspended in buffer $\mathrm{A}(500 \mathrm{mM} \mathrm{NaCl}, 20 \mathrm{mM}$ Tris- $\mathrm{HCl}, \mathrm{pH}$

581 7.5), and then lysed by sonication. The supernatant was loaded into a HisTrap

582 column (GE Healthcare) and washed with buffer A and buffer B (buffer A plus 50

$583 \mathrm{mM}$ immidazol). The target protein was finally eluted with buffer $\mathrm{C}$ (buffer A plus

$584500 \mathrm{mM}$ immidazol). The eluted protein was dialyzed against buffer $A$ and

585 digested with Ulp1 protease. The His-Sumo tag was removed by passing the

586 digestion product through a second step HisTrp column. The flow-through protein

587 was dialyzed against buffer $\mathrm{D}$ (100 mM NaCl, $20 \mathrm{mM} \mathrm{HEPES,} \mathrm{pH} \mathrm{7.0,} 5$ mM DTT)

588 and loaded onto a Heparin column (GE Healthcare). A linear gradient from buffer

589 D to buffer $\mathrm{E}(2 \mathrm{M} \mathrm{NaCl}, 20 \mathrm{mM} \mathrm{HEPES}, \mathrm{pH}$ 7.0) was applied to elute the target

590 protein. The eluted protein was further purified using a Superdex G200 column

591 with buffer $\mathrm{E}$ ( $50 \mathrm{mM} \mathrm{NaCl}, 20 \mathrm{mM} \mathrm{HEPES}, \mathrm{pH}$ 7.0, $5 \mathrm{mM} \mathrm{DTT}$ ) and concentrated

592 to $10 \mathrm{mg} / \mathrm{ml}$ for further use. The mutated forms of the MBD domain of RMB1 were

593 expressed and purified following the same protocol.

594 The MST assay was performed using a Monolith NT.115 instrument (NanoTemper

595 Technologies) (Jerabek-Willemsen et al. 2014; Harris et al. 2018). The purified

596 MBD domain of RMB1 was half-and-half diluted in 14 steps with the buffer $E$,

597 covering a concentration range from about $50 \mu \mathrm{M}$ to $1.5 \mathrm{nM}$ (Figure $4 \mathrm{C}$ ). For each

598 DNA duplex, one DNA strand is labeled with Biotin at the $5^{\prime}$ during the synthesis 
599 (Figure 4C). The Biotin labeled strand and the unlabeled complementary strand

600 were annealed together and further mixed with the diluted protein steps. The

601 mixture was loaded into the MST capillaries. Three repeats for each

602 measurement were conducted. The data were analyzed using the NanoTemper

603 analysis software (NanoTemper Technologies).

\section{Pto DC3000 bacterial infection assays}

605 Pto DC3000 bacterial infection assays were performed according to (Ishiga et al.

606 2011) with some modifications. Briefly, the indicated mutants were germinated

607 and grown on 1/2 MS medium. A single colony of Pto DC3000 was inoculated

608 onto new mannitol-glutamate medium agar with rifampicin $(50 \mu \mathrm{g} / \mathrm{ml})$ and

609 streaked on the plate. The plate was inoculated at $28^{\circ} \mathrm{C}$ for 36 hours. The

610 collected bacterial colonies were suspended in an appropriate volume of sterile

611 distilled water. $40 \mathrm{ml}$ of a Pto DC3000 bacterial suspension ( $4 \times 10^{6} \mathrm{CFU}$, colony

612 forming units) were poured onto the plate containing 3-week-old Arabidopsis

613 seedlings and incubated for 2 minutes at room temperature. The bacterial

614 suspension was then removed by pipetting and the plates were sealed with 3M

615 Micropore $2.5 \mathrm{~cm}$ surgical tape. The infected seedlings were incubated in

616 long-day (16-h light / 8-h dark) conditions at $22{ }^{\circ} \mathrm{C}$ for three days. The

617 development of symptoms was evaluated and photographed at 3

618 days-post-inoculation (dpi). Bacterial growth was evaluated according to (Ishiga et

619 al. 2011).

\section{0 mRNA-seq analysis}

621 For mRNA-seq analyses, total RNA was extracted from 2-week-old seedlings with

622 the RNeasy plant kit (Qiagen), and subjected to RNA deep sequencing. Three

623 biological replicates were performed per genotype. The libraries were constructed

624 and sequenced at the Genomics Core Facility of the Shanghai Centre for Plant 
625 Stress Biology, Chinese Academy of Sciences, using an Illumina HiSeq2500.

626 Low-quality sequences $(q<20)$ and adapters were trimmed using Trimmomatic

627 and cutadpte (Bolger et al. 2014). Clean reads were mapped to the Arabidopsis

628 reference genome (TAIR10) using STAR (Dobin et al. 2013). DESeq2 was used to

629 detect differentially expressed genes according to adjusted p value (padj)

630 threshold of $<0.01$ (Love et al. 2014).

631

\section{SUPPLEMENTAL INFORMATION}

633 Supplemental Information includes Figures S1-S7 and Tables S1-S3, and can be 634 found with this article online.

\section{AUTHOR CONTRIBUTIONS}

637 J.-K.Z. and P.L. designed the study. P.L., W.-F.N., X.X., Y.W., Y.J., P.H., X.L., G.Q., 638 H.H., J.D., and Z.L. performed the experiments. P.L., W.-F.N., and J.-K.Z.

639 analyzed the data. W.-F.N., R.L.-D., and J.-K.Z. wrote the manuscript.

\section{ACKNOWLEDGEMENTS}

642 This work was supported by the Chinese Academy of Sciences, National Nature

643 Science Foundation of China (32002046), and Natural Science Foundation of

644 Jiangsu Province (BK20200948).

\section{References}

647 Bai G, Yang DH, Zhao Y, Ha S, Yang F, Ma J, Gao XS, Wang ZM, Zhu JK (2013) 648 Interactions between soybean $\mathrm{ABA}$ receptors and type $2 \mathrm{C}$ protein phosphatases. 649 Plant Mol Biol 83: 651-664

650 Bolger AM, Lohse M, Usadel B (2014) Trimmomatic: a flexible trimmer for Illumina 651 sequence data. Bioinformatics 30: 2114-2120

652 Cao X, Jacobsen SE (2002) Locus-specific control of asymmetric and CpNpG 
653 methylation by the DRM and CMT3 methyltransferase genes. Proc Natl Acad Sci U S

654 A 99 Suppl 4: 16491-16498

655 Choi Y, Gehring M, Johnson L, Hannon M, Harada JJ, Goldberg RB, Jacobsen SE, Fischer

656 RL (2002) DEMETER, a DNA glycosylase domain protein, is required for endosperm 657 gene imprinting and seed viability in arabidopsis. Cell 110: 33-42

658 Clough SJ, Bent AF (1998) Floral dip: a simplified method for 659 Agrobacterium-mediated transformation of Arabidopsis thaliana. Plant J 16: $660735-743$

661 Costa Y, Ding J, Theunissen TW, Faiola F, Hore TA, Shliaha PV, Fidalgo M, Saunders A, 662 Lawrence M, Dietmann S, Das S, Levasseur DN, Li Z, Xu M, Reik W, Silva JC, Wang J 663 (2013) NANOG-dependent function of TET1 and TET2 in establishment of 664 pluripotency. Nature 495: 370-374

665 de la Rica L, Rodriguez-Ubreva J, Garcia M, Islam AB, Urquiza JM, Hernando H, 666 Christensen J, Helin K, Gomez-Vaquero C, Ballestar E (2013) PU.1 target genes 667 undergo Tet2-coupled demethylation and DNMT3b-mediated methylation in 668 monocyte-to-osteoclast differentiation. Genome Biol 14: R99

669 Dobin A, Davis CA, Schlesinger F, Drenkow J, Zaleski C, Jha S, Batut P, Chaisson M, 670 Gingeras TR (2013) STAR: ultrafast universal RNA-seq aligner. Bioinformatics 29: $671 \quad 15-21$

672 Dowen RH, Pelizzola M, Schmitz RJ, Lister R, Dowen JM, Nery JR, Dixon JE, Ecker JR 673 (2012) Widespread dynamic DNA methylation in response to biotic stress. Proc Natl 674 Acad Sci U S A 109: E2183-2191

675 Duan CG, Wang X, Tang K, Zhang H, Mangrauthia SK, Lei M, Hsu CC, Hou YJ, Wang C, 676 Li Y, Tao WA, Zhu JK (2015) MET18 Connects the Cytosolic Iron-Sulfur Cluster 677 Assembly Pathway to Active DNA Demethylation in Arabidopsis. PLoS Genet 11: 678 e1005559

679 Duan CG, Wang X, Xie S, Pan L, Miki D, Tang K, Hsu CC, Lei M, Zhong Y, Hou YJ, Wang 680 Z, Zhang Z, Mangrauthia SK, Xu H, Zhang H, Dilkes B, Tao WA, Zhu JK (2017) A pair of 681 transposon-derived proteins function in a histone acetyltransferase complex for 682 active DNA demethylation. Cell Res 27: 226-240

683 Finnegan EJ, Dennis ES (1993) Isolation and identification by sequence homology of a 684 putative cytosine methyltransferase from Arabidopsis thaliana. Nucleic Acids Res 21: $685 \quad 2383-2388$

686 Furner IJ, Matzke M (2011) Methylation and demethylation of the Arabidopsis 687 genome. Curr Opin Plant Biol 14: 137-141

688 Gehring M, Huh JH, Hsieh TF, Penterman J, Choi Y, Harada JJ, Goldberg RB, Fischer RL 689 (2006) DEMETER DNA glycosylase establishes MEDEA polycomb gene 690 self-imprinting by allele-specific demethylation. Cell 124: 495-506

691 Gong Z, Morales-Ruiz T, Ariza RR, Roldan-Arjona T, David L, Zhu JK (2002) R0S1, a 
692 repressor of transcriptional gene silencing in Arabidopsis, encodes a DNA

693 glycosylase/lyase. Cell 111: 803-814

694 Haag JR, Pikaard CS (2011) Multisubunit RNA polymerases IV and V: purveyors of

695 non-coding RNA for plant gene silencing. Nat Rev Mol Cell Biol 12: 483-492

696 Harris CJ, Scheibe M, Wongpalee SP, Liu WL, Cornett EM, Vaughan RM, Li XQ, Chen W,

697 Xue Y, Zhong ZH, Yen LD, Barshop WD, Rayatpisheh S, Gallego-Bartolome J, Groth M,

698 Wang ZH, Wohlschlegel JA, Du JM, Rothbart SB, Butter F, Jacobsen SE (2018) A DNA

699 methylation reader complex that enhances gene transcription. Science 362: 1182-+

700 He XJ, Chen T, Zhu JK (2011) Regulation and function of DNA methylation in plants

701 and animals. Cell Res 21: 442-465

702 Hsieh TF, Ibarra CA, Silva P, Zemach A, Eshed-Williams L, Fischer RL, Zilberman D

703 (2009) Genome-wide demethylation of Arabidopsis endosperm. Science 324:

704 1451-1454

705 Ishiga Y, Ishiga T, Uppalapati SR, Mysore KS (2011) Arabidopsis seedling

706 flood-inoculation technique: a rapid and reliable assay for studying plant-bacterial

707 interactions. Plant Methods 7:

708 Jerabek-Willemsen M, Andre T, Wanner R, Roth HM, Duhr S, Baaske P, Breitsprecher

709 D (2014) MicroScale Thermophoresis: Interaction analysis and beyond. J Mol Struct

710 1077: 101-113

711 Jung M, Pfeifer GP (2015) Aging and DNA methylation. BMC Biol 13: 7

712 Klutstein M, Nejman D, Greenfield R, Cedar H (2016) DNA Methylation in Cancer and

713 Aging. Cancer Res 76: 3446-3450

714 Lang Z, Lei M, Wang X, Tang K, Miki D, Zhang H, Mangrauthia SK, Liu W, Nie W, Ma G,

715 Yan J, Duan CG, Hsu CC, Wang C, Tao WA, Gong Z, Zhu JK (2015) The

716 methyl-CpG-binding protein MBD7 facilitates active DNA demethylation to limit DNA

717 hyper-methylation and transcriptional gene silencing. Mol Cell 57: 971-983

718 Law JA, Ausin I, Johnson LM, Vashisht AA, Zhu JK, Wohlschlegel JA, Jacobsen SE

719 (2010) A protein complex required for polymerase $\mathrm{V}$ transcripts and RNA- directed

720 DNA methylation in Arabidopsis. Curr Biol 20: 951-956

721 Law JA, Jacobsen SE (2010) Establishing, maintaining and modifying DNA

722 methylation patterns in plants and animals. Nat Rev Genet 11: 204-220

723 Lei M, Zhang H, Julian R, Tang K, Xie S, Zhu JK (2015) Regulatory link between DNA

724 methylation and active demethylation in Arabidopsis. Proc Natl Acad Sci U S A 112:

$725 \quad 3553-3557$

726 Love MI, Huber W, Anders S (2014) Moderated estimation of fold change and 727 dispersion for RNA-seq data with DESeq2. Genome Biol 15: 550

728 Matzke MA, Mosher RA (2014) RNA-directed DNA methylation: an epigenetic 729 pathway of increasing complexity. Nat Rev Genet 15: 394-408

730 Nie WF, Lei M, Zhang M, Tang K, Huang H, Zhang C, Miki D, Liu P, Yang Y, Wang X, 
731 Zhang H, Lang Z, Liu N, Xu X, Yelagandula R, Zhang H, Wang Z, Chai X, Andreucci A, Yu

732 JQ Berger F, Lozano-Duran R, Zhu JK (2019) Histone acetylation recruits the SWR1

733 complex to regulate active DNA demethylation in Arabidopsis. Proc Natl Acad Sci U S

734 A:

735 Penterman J, Zilberman D, Huh JH, Ballinger T, Henikoff S, Fischer RL (2007) DNA

736 demethylation in the Arabidopsis genome. Proc Natl Acad Sci U S A 104: 6752-6757

737 Qian W, Miki D, Lei M, Zhu X, Zhang H, Liu Y, Li Y, Lang Z, Wang J, Tang K, Liu R, Zhu JK

738 (2014) Regulation of active DNA demethylation by an alpha-crystallin domain protein

739 in Arabidopsis. Mol Cell 55: 361-371

740 Qian W, Miki D, Zhang H, Liu Y, Zhang X, Tang K, Kan Y, La H, Li X, Li S, Zhu X, Shi X,

741 Zhang K, Pontes O, Chen X, Liu R, Gong Z, Zhu JK (2012) A histone acetyltransferase

742 regulates active DNA demethylation in Arabidopsis. Science 336: 1445-1448

743 Qin G, Ma J, Chen X, Chu Z, She YM (2017) Methylated-antibody affinity purification to

744 improve proteomic identification of plant RNA polymerase Pol V complex and the

745 interacting proteins. Sci Rep 7: 42943

746 Robertson KD (2005) DNA methylation and human disease. Nat Rev Genet 6:

$747 \quad 597-610$

748 Sardina JL, Colbmbet S, Tian TV, Gomez A, Di Stefano B, Berenguer C, Brumbaugh J,

749 Stadhouders R, Segura-Morales C, Gut M, Gut IG, Heath S, Aranda S, Di Croce L,

750 Hochedlinger K, Thieffry D, Graf T (2018) Transcription Factors Drive Tet2-Mediated

751 Enhancer Demethylation to Reprogram Cell Fate. Cell Stem Cell 23: 905-906

752 Slotkin RK, Martienssen R (2007) Transposable elements and the epigenetic

753 regulation of the genome. Nat Rev Genet 8: 272-285

754 Wang D, Xia X, Weiss RE, Refetoff S, Yen PM (2010) Distinct and histone-specific

755 modifications mediate positive versus negative transcriptional regulation of

756 TSHalpha promoter. PLoS One 5: e9853

757 Wang Y, Xiao M, Chen X, Chen L, Xu Y, Lv L, Wang P, Yang H, Ma S, Lin H, Jiao B, Ren R,

758 Ye D, Guan KL, Xiong Y (2015) WT1 recruits TET2 to regulate its target gene

759 expression and suppress leukemia cell proliferation. Mol Cell 57: 662-673

760 Williams BP, Pignatta D, Henikoff S, Gehring M (2015) Methylation-sensitive

761 expression of a DNA demethylase gene serves as an epigenetic rheostat. PLoS Genet

762 11: e1005142

763 Wu X, Zhang Y (2017) TET-mediated active DNA demethylation: mechanism, function 764 and beyond. Nat Rev Genet 18: 517-534

765 Xiong J, Zhang Z, Chen J, Huang H, Xu Y, Ding X, Zheng Y, Nishinakamura R, Xu GL,

766 Wang H, Chen S, Gao S, Zhu B (2016) Cooperative Action between SALL4A and TET

767 Proteins in Stepwise 0xidation of 5-Methylcytosine. Mol Cell 64: 913-925

768 Yang J, Liu Y, Yan H, Tian T, You Q, Zhang L, Xu W, Su Z (2018) PlantEAR: Functional

769 Analysis Platform for Plant EAR Motif-Containing Proteins. Front Genet 9: 590 
770 Yu A, Lepere G, Jay F, Wang J, Bapaume L, Wang Y, Abraham AL, Penterman J, Fischer

771 RL, Voinnet 0, Navarro L (2013) Dynamics and biobgical relevance of DNA 772 demethylation in Arabidopsis antibacterial defense. Proc Natl Acad Sci U S A 110:

773 2389-2394

774 Zemach A, Grafi G (2007) Methyl-CpG-binding domain proteins in plants: interpreters 775 of DNA methylation. Trends Plant Sci 12: 80-85

776 Zemach A, Kim MY, Hsieh PH, Coleman-Derr D, Eshed-Williams L, Thao K, Harmer SL, 777 Zilberman D (2013) The Arabidopsis nucleosome remodeler DDM1 allows DNA

779 methyltransferases to access H1-containing heterochromatin. Cell 153: 193-205

780 Zhang H, Lang Z, Zhu JK (2018) Dynamics and function of DNA methylation in plants. Nat Rev Mol Cell Biol 19: 489-506

782 Zhu J, Kapoor A, Sridhar VV, Agius F, Zhu JK (2007) The DNA glycosylase/lyase ROS1 functions in pruning DNA methylation patterns in Arabidopsis. Curr Biol 17: 54-59

784 Zhu JK (2009) Active DNA demethylation mediated by DNA glycosylases. Annu Rev

\section{FIGURE LEGENDS}

\section{Figure 1. RWD40 interacts with ROS1.}

797 (A) Schematic representation of the RWD40 protein (top panel) and of the

798 truncated forms of RWD40 used in Y2H assays (lower panels). The two

799 LISH-CTLH-containing regions of RWD40 encompass amino acid residues 7 to

80095 and 191 to 279, respectively. The WD40 domain encompasses amino acid

801 residues 388 to 741 . LI-CT indicates the LISH-CTLH domain. aa, amino acid 
802 residue.

803 (B) RWD40 interacts with ROS1 in Y2H assays. The N-terminal region, including 804 the two LISH-CTLH domains of RWD40, interacts with ROS1.

805 (C) RWD40 interacts with ROS1 in BiFC assays.

806 (D) Proteins detected by LC-MS/MS following immunoprecipitation (IP) using an 807 anti-FLAG antibody, which immunopurifies ROS1, RWD40, RMB1, and RHD1 808 from transgenic Arabidopsis lines. Results obtained in one to four independent 809 biological replicates are shown (Rep1-Rep4).

810

811 Figure 2. RMB1 and RHD1 interact with RWD40 but not with ROS1.

812 (A) Interactions among RWD40, RMB1, RHD1, and ROS1 in Y2H assays. BD, 813 GAL4-binding domain; AD, GAL4-activation domain.

814 (B) Interactions among RWD40, RMB1, RHD1, and ROS1 in split luciferase 815 complementation assays. The indicated proteins were fused to the $\mathrm{N}$-terminal or 816 the C-terminal part of the luciferase protein (nLuc or cLuc, respectively) and 817 transiently expressed in Nicotiana benthamiana leaves. White circles indicate 818 regions infiltrated with Agrobacterium. The luminescent signal indicates a 819 protein-protein interaction.

820 (C) Schematic representation of the truncated forms of RWD40 used in the Y2H 821 assays. WID, WD40-interaction domain. aa, amino acid residue.

822 (D) The WID domain of RMB1 interacts with the WD40 domain of RWD40 in Y2H 823 assays.

825 Figure 3. ROS1, RWD40, RMB1, and RHD1 form a protein complex.

826 (A) Western blot analysis of gel filtration eluates. The indicated fractions eluted 827 from the gel filtration column were probed with anti-MYC or anti-FLAG to detect 
828 the epitope-tagged RWD40, RMB1, RHD1, and ROS1. The arrow indicates the 829 estimated molecular weight of the protein complex. A 120-ml column of HiPrep $83016 / 60$ Sephacryl S-300 HR was used. The elution volumes corresponding to the 831 indicated fraction No. and indicated molecular weight of standards are shown.

832 (B) Co-expression of full-length $R W D 40, R M B 1, R H D$, and a truncated $R O S 1$ 833 protein (amino acid residues 1-100) in an insect cell expression system. RWD40, $834 \mathrm{RMB1}, \mathrm{RHD}$, and the truncated ROS1 were obtained in a single peak fraction. 835 The positions of elution markers and their molecular masses (in kDa) are 836 indicated. a.u., arbitrary units. A 24-ml column of Superdex200 10/300 GL was 837 used for the Sf9 recombinant proteins.

839 Figure 4. RMB1 binds to methylated DNA.

840 (A,B) Electrophoretic mobility shift assay (EMSA) showing that the MBD domain 841 of RMB1 (residues 1 to 81 ) binds to methylated oligonucleotides corresponding to 842 the AT5G39160 locus (A) and the MEMS in the ROS1 promoter (B). M, 843 methylated; U, unmethylated.

844 (C) RMB1 binding to labeled methyl-DNA sequence corresponding to the 845 AT5G39160 locus assessed by microscale thermophoresis (MST). MST binding 846 assays were used to quantify the interaction of RMB1 with an unmethylated (Um) 847 probe or probes methylated $(\mathrm{m})$ in $\mathrm{CG}, \mathrm{CHG}$, or $\mathrm{CHH}$ contexts. The W22G, Y38F, $848 \mathrm{~T} 49 \mathrm{~A}$, or K50T mutations in conserved residues in the MBD domain abolished or 849 diminished the binding to methylated DNA. The detailed sequence information in 850 each probe is displayed. The cytosine is labeled in the $\mathrm{CHH}$ context in the forward 851 strand of the $\mathrm{mCHH}$ probe, but not in the complementary strand. Values are 852 means \pm SD $(n=3)$. Curves indicate calculated fits; calculated binding affinities are 853 displayed. 
855 Figure 5. RWD40, RMB1, and RHD1 function in active DNA methylation.

856 (A) Bisulfite sequencing data showing DNA methylation in different sequence

857 contexts at the MEMS in the ROS1 promoter in wild-type Col-0 and the indicated 858 mutants.

859 (B) Relative expression of ROS1 in the indicated samples. Values are means \pm $860 \mathrm{SD}$ of three biological replicates. ${ }^{*} \mathrm{P}<0.05$, ${ }^{* \star} \mathrm{P}<0.01$, compared with wild-type 861 Col-0 plants; NS, not significantly different compared with wild-type Col-0 plants 862 (2-tailed t test).

863 (C) Enrichment of RWD40, RMB1, RHD1, and ROS1 at the MEMS in the ROS1 864 promoter detected by ChIP-qPCR assays. The ChIP signal was quantified relative 865 to input DNA. The no antibody precipitates served as negative control. Actin 2 866 was used as a control region. Values are means \pm SD of three technical replicates. 867 Results of two biological replicates are displayed. "Rep" indicates replicate.

868 (D) Effect of mutations in RWD40, RMB1, and RHD1 on ROS1 protein enrichment 869 at the MEMS in the ROS1 promoter by ChIP-qPCR assays.

870 (E) Chop-PCR showing that $r w d 40-1, r m b 1-1$, rhd1-1, and ros 1-4 mutants 871 displayed an increased methylation phenotype at the indicated loci. Amplification 872 of non-digested DNA served as a control.

873 (F) Analysis of DNA methylation levels at several DNA demethylation target loci in 874 wild-type Col-0 control plants and the indicated mutants by individual locus 875 bisulfite sequencing analysis.

877 Figure 6. The RWD40 complex regulates gene expression and antibacterial 878 resistance.

879 (A) Number of differentially expressed genes identified in $r w d 40$ rmb1 rhd1 and 
880 ros 1-4 mutants by mRNA-seq.

881 (B) Overlap of up-regulated or down-regulated genes between rwd40 rmb1 rhd 1 882 and ros 1-4 mutants.

883 (C) Validation of the down-regulation of six genes in rwd40 rmb1 rhd1 and ros1-4

884 mutants by qRT-PCR. Values are means \pm SD of 3 biological replicates relative to 885 transcript levels in wild-type Col-0 plants. ${ }^{*} \mathrm{P}<0.05$, compared with Col-0 samples 886 (2-tailed t test).

887 (D) Phenotypes of Col-0, ros 1-4, rwd40-1, rmb1-1, rhd1-1, and rwd40 rmb1 rhd 888 plants inoculated with Pto DC3000. Pictures were taken at 3-d post-inoculation 889 (dpi).

890 (E) Bacterial counts in Col-0 and the indicated mutants plants at 3 dpi. ${ }^{* *} \mathrm{P}<0.01$, 891 compared with Col-0 samples (2-tailed t test).

892 Figure 7. Schematic model showing that RWD40 may inhibit its own 893 function by targeting the MEMS at the ROS1 promoter.

894 The RWD40 complex decreases the DNA methylation level of the MEMS site at 895 the ROS1 promoter, causing reduced ROS1 expression. The reduced ROS1 896 expression would hinder the DNA demethylation function of the RWD40 complex 897 at target genomic loci.

899 Figure S1. DNA demethylation phenotypes of rwd40-1 and rwd40-2 mutants 900 and mutant complementation.

901 (A) RWD40 localization in Nicotiana benthamiana.

902 (B) T-DNA insertion position in rwd40-1 and rwd40-2 mutants. Boxes and lines 903 denote exons and introns, respectively.

904 (C) Expression of RWD40 in mutants relative to that in wild-type Col-0 control 
905 plants, as measured by qRT-PCR. Values are means \pm SD of three biological 906 replicates.

907 (D) Western blot analysis of RWD40-3xFLAG in T2 rwd40-1 transgenic lines.

908 (E) DNA methylation levels in rwd40 mutant alleles and complementation lines at

909 the AT5G39160 locus as determined by Chop-PCR.

910 (F) DNA methylation levels at the AT5G39160 locus in $r w d 40-1$ and $r w d 40-2$

911 mutants as determined by individual bisulfite sequencing.

912

913 Figure S2. Characterization of RMB1 and RHD1.

914 (A) RMB1 domains and mutants. Upper panel, schematic representation of the

915 RMB1 protein. CBD, C (AT)-rich DNA-binding domain. Middle panel, T-DNA

916 insertion positions in rmb1-1 and rmb1-2 mutants. Boxes and lines denote exons

917 and introns, respectively. Lower panel, RMB1 transcript levels in the mutants.

918 (B) Schematic representation of the RMB1 protein (upper panel), T-DNA insertion

919 position in the rhd1-1 mutant (middle panel), and RHD1 transcripts levels in the

920 rhd1-1 mutant by RT-PCR detection (lower panel).

921 (C) Interactions among RWD40, RMB1, and RHD1 in BiFC assays.

922 (D) DNA methylation levels in rmb1 mutant alleles and in complementation lines at

923 the AT5G39160 locus as determined by Chop-PCR.

924 (E) DNA methylation levels at the AT5G39160 locus in rmb1-1 and rmb1-2

925 mutants as determined by individual locus bisulfite sequencing.

926 (F) DNA methylation levels in wild-type Col-0 and indicated mutants at the

927 AT5G39160 locus (upper panel), and in rhd1 mutant alleles and complementation

928 line at the AT4G18380 locus as determined by Chop-PCR (lower panel). 


\section{1 assays.}

932 (A) Schematic representation of the truncated forms of ROS1 used in the $\mathrm{Y} 2 \mathrm{H}$

933 assays and of the ELM domain identified in N-terminal regions of ROS1.

$934 \mathrm{HhH}-\mathrm{GPD}$, hallmark Helix-hairpin-helix and Gly/Pro-rich loop domain; EndIIII,

935 endonuclease III; Perm-CXXC, permuted version of a single unit of the zinc

936 finger-CXXC; RRM_DME, RRM-fold domain present at the C-terminus of

937 Demeter-like glycoslyases; EAR, ethylene response factor-associated amphiphilic

938 repression domain; ELD, EAR-like motif.

939 (B) The ELD domain of ROS1 interacts with RWD40 in Y2H assays.

940 (C) Schematic representation of the truncated forms of RHD1 used in Y2H

941 assays.

942 (D) RHD1 interacts with RHD1 through the zinc-finger domain, and the WD40

943 domain of RWD40 interacts with the zinc-finger domain of RHD1 in Y2H assays.

944 (E) RMB1 interacts with full-length RHD1 but does not interact with its zinc-finger

945 domain or homeodomain.

947 Figure S4. Analysis of MBD domain-containing proteins in Arabidopsis.

948 (A) Phylogenetic tree of MBD domain-containing proteins in A. thaliana.

949 (B) Alignment of MBD domains in MBD domain-containing proteins in A. thaliana.

950 The amino acid residues targeted for mutations in the MBD domain are indicated

951 by triangles.

952

953 Figure S5. Mutation of the MBD domain reduces the binding of RMB1 to

954 methylated DNA and abolishes the demethylation function of RMB1.

955 (A) DNA methylation level at AT5G39160 in the rmb1-1 mutant and in the rmbd1-1

956 mutant expressing WT (wild-type) or K50T-mutated RMB1 as determined by 
957 Chop-PCR.

958 (B,C) EMSA of the MBD domain of MBD7 (C) and IDM1 (D) binding to methylated

959 oligonucleotides corresponding to the AT5G39160 locus. M, methylated. Um,

960 unmethylated.

961

962 Figure S6. Dysfunction of RWD40, RMB1, or RHD1 does not cause silencing 963 of the 35S:SUC2 transgene.

964 (A) Chop-PCR showing that $r w d 40-1, r m b 1-1$, and $r h d 1-1$ mutants do not display

965 an increased methylation phenotype in IDM1-dependent DNA demethylation

966 target loci (Qian et al. 2012). Amplification of non-digested DNA served as a 967 control.

968 (B) Root phenotype in $r w d 40-1, r m b 1-1$, and $r h d 1-1$ in the 35S:SUC2 transgenic 969 background.

970 (C) Relative expression of the 35S:SUC2 transgene in the indicated mutants.

971 Values are relative to transcript levels in 35S:SUC2 control plants and are means

$972 \pm$ SD of three biological replicates. ${ }^{*} \mathrm{P}<0.01$, compared with 35S:SUC2 plants;

973 NS, not significantly different compared with 35S:SUC2 plants (2-tailed t test).

974 (D) Screenshots of DNA cytosine methylation status in Col-0, idm1-2, and ros 1-4, 975 and screenshots of H2A.Z deposition and H3K18Ac in wild-type control plants 976 (Nie et al., 2019) at the tested loci in Figure 5. AT1G62760 is an IDM1-dependent 977 active DNA demethylation target (Qian et al., 2012, Nie et al., 2019), and serves 978 as a positive control of the co-existence of H2A.Z and H3K18ac. 
bioRxiv preprint doi: https://doi.org/10.1101/2020.02.21.958371; this version posted December 7, 2020. The copyright holder for this preprint (which was not certified by peer review) is the author/funder. All rights reserved. No reuse allowed without permission.

Figure 1

A

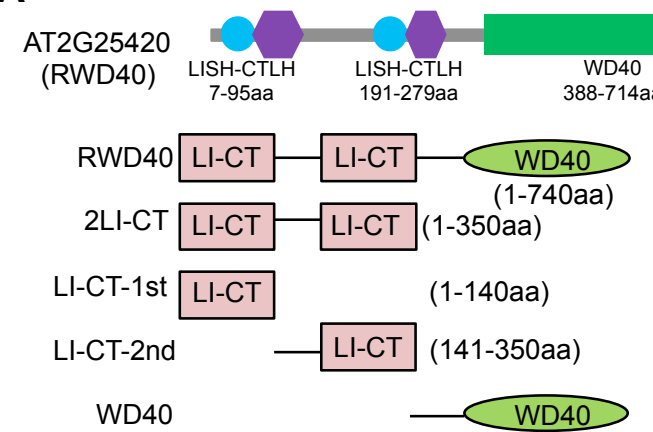
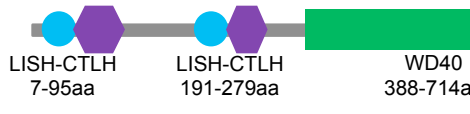

B
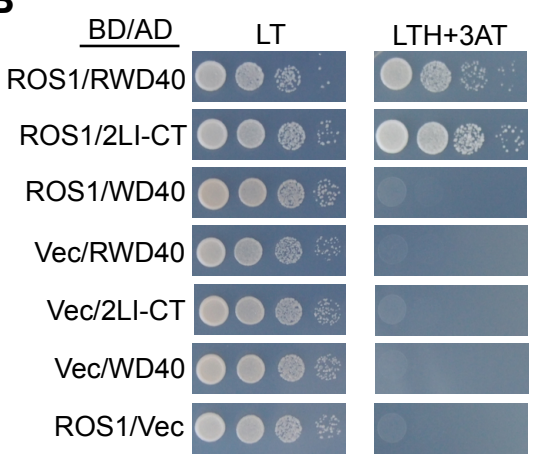

\section{C}
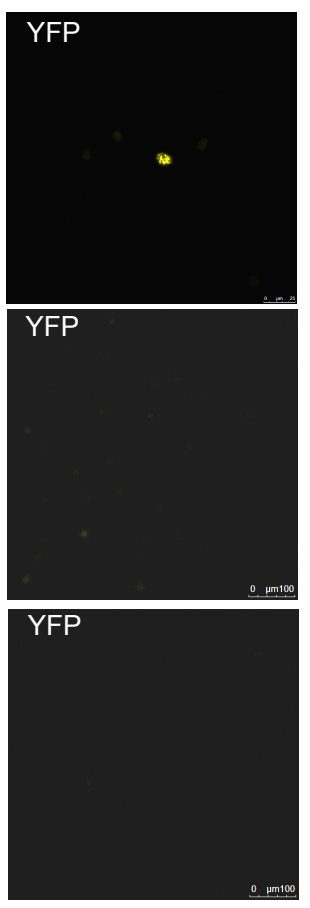

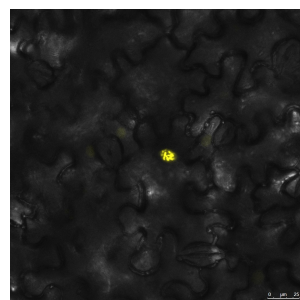

YFPN-ROS1

YFPC-RWD40
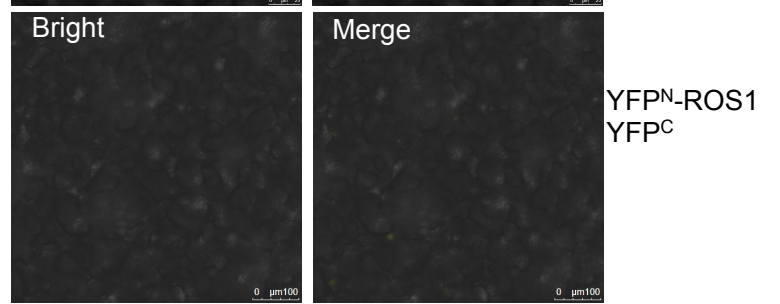

YFPC
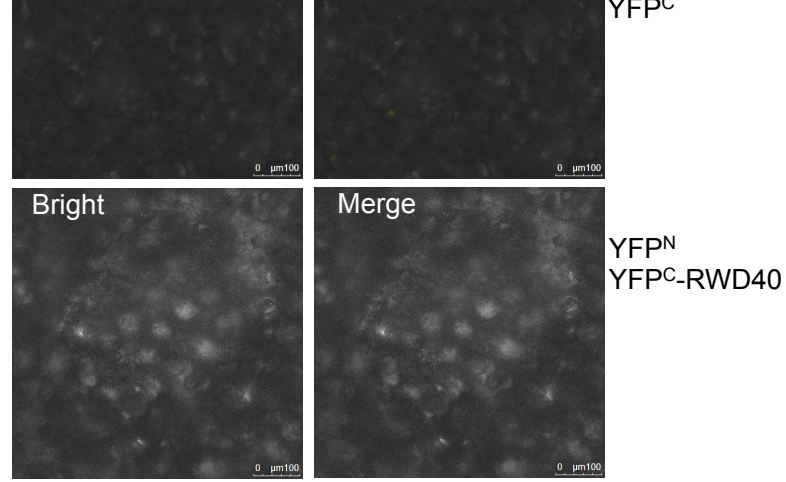

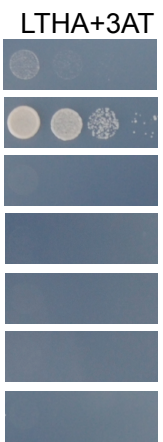

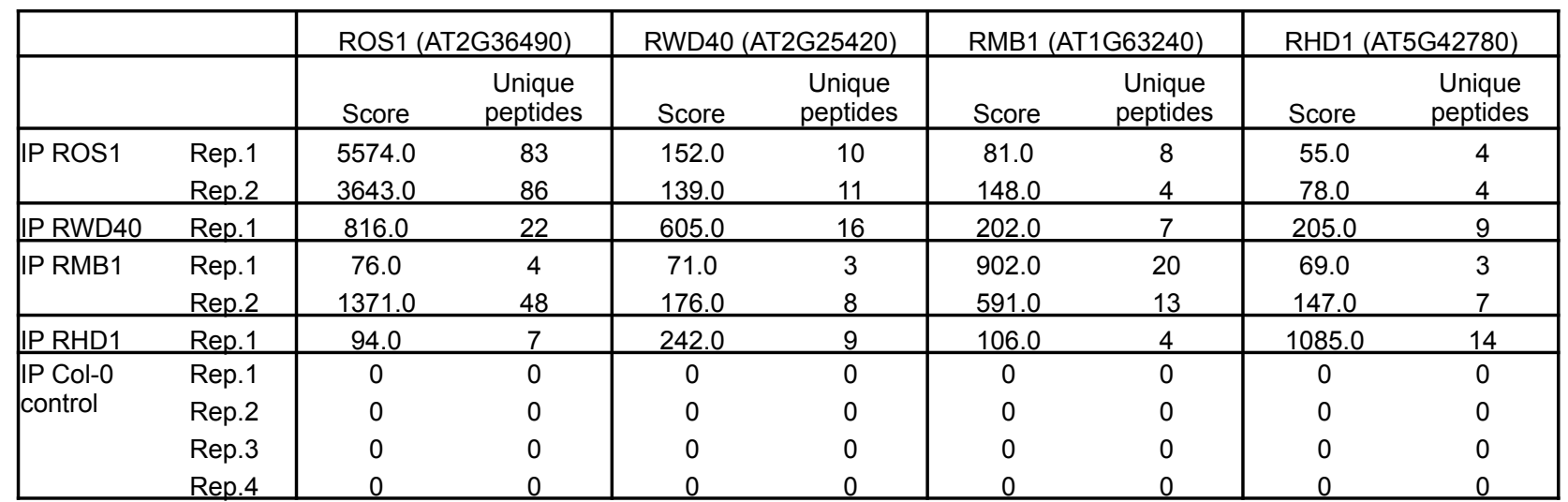




\section{Figure 2}
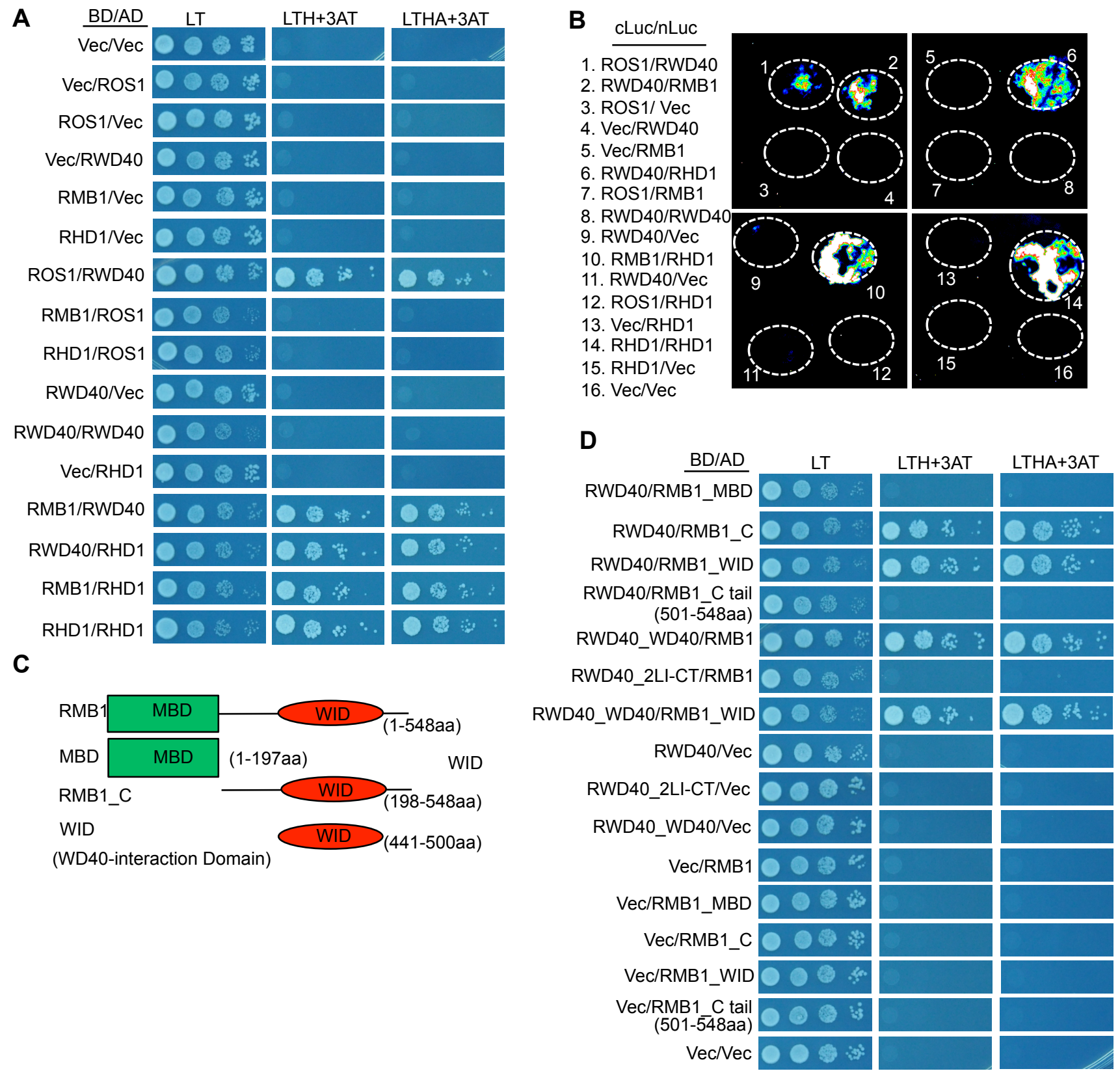


\section{Figure 3}

A

Gel filtration

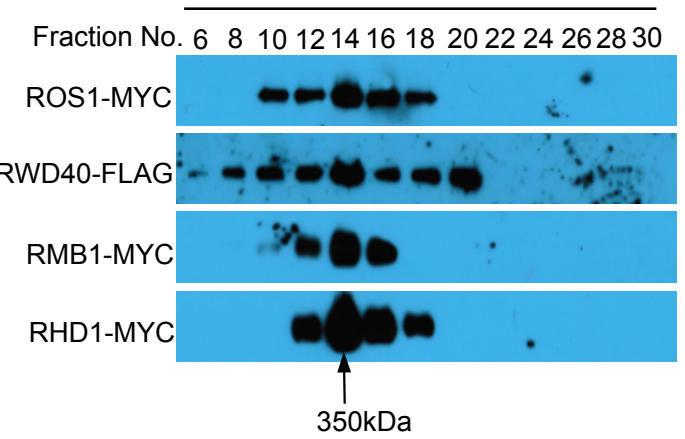

The elution volumes corresponding to indicated fraction No.

\begin{tabular}{|c|c|c|c|}
\hline Fraction No. & 12 & 14 & 16 \\
\hline Elution Volumes (ml) & 54 & 58 & 62 \\
\hline
\end{tabular}

The elution volumes corresponding to indicated molecular weight of standards

\begin{tabular}{|c|c|c|c|}
\hline $\begin{array}{c}\text { Molecular Weight } \\
(\mathrm{KDa})\end{array}$ & 443 & 350 & 150 \\
\hline Elution Volumes (ml) & 53 & 58 & 68 \\
\hline
\end{tabular}

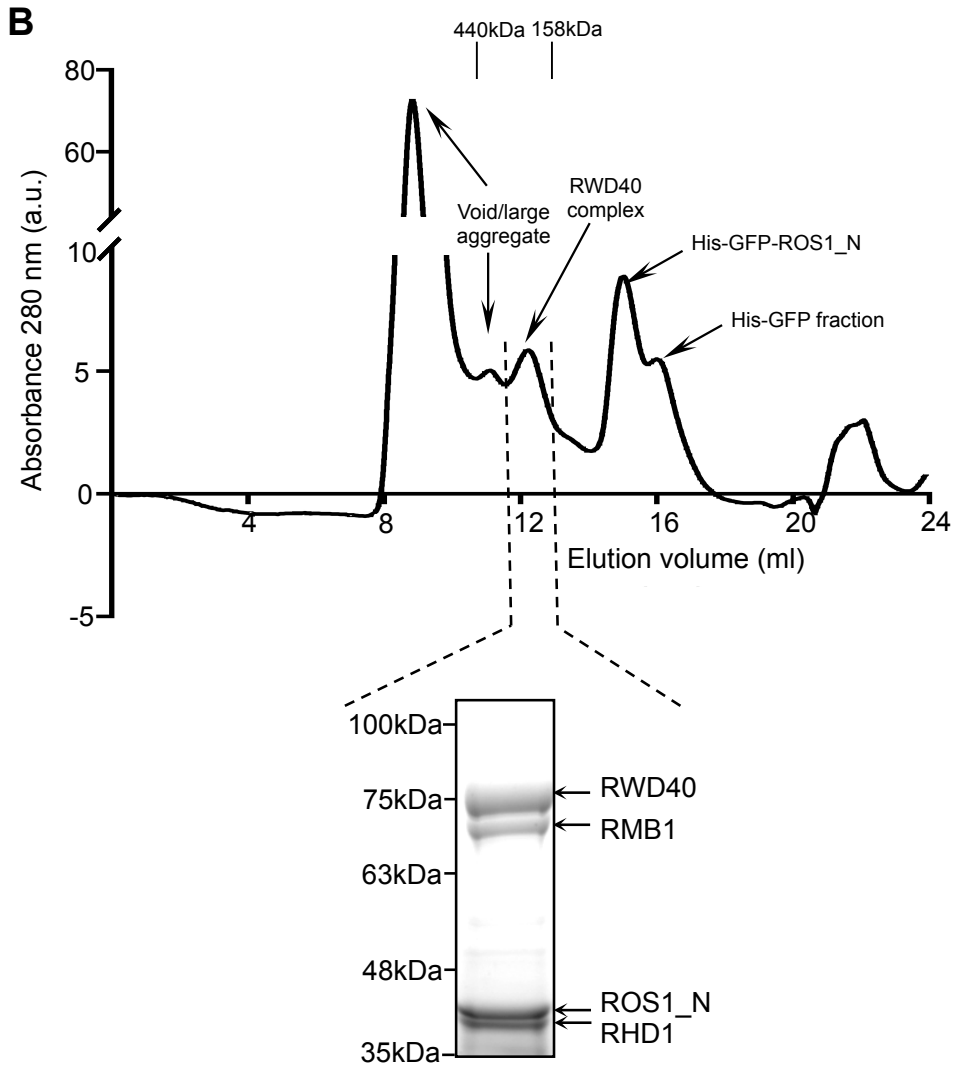




\section{Figure 4}

A

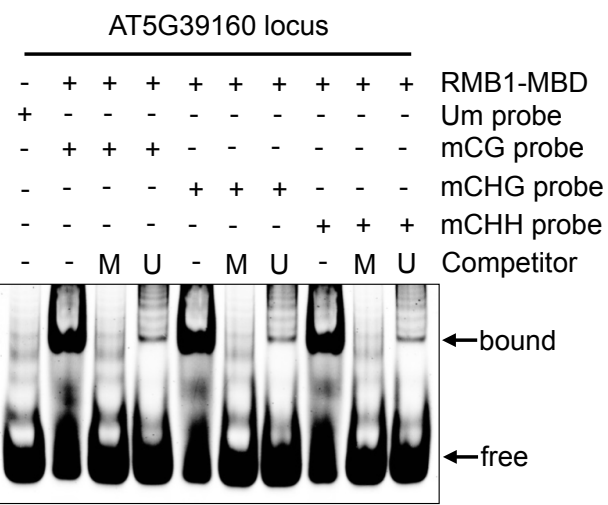

B

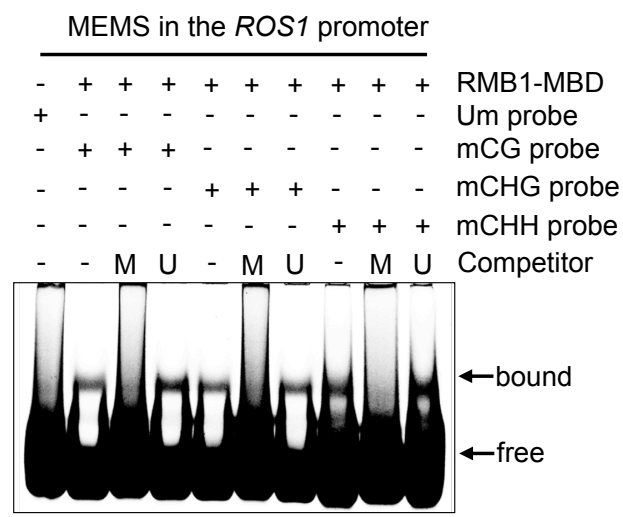

C
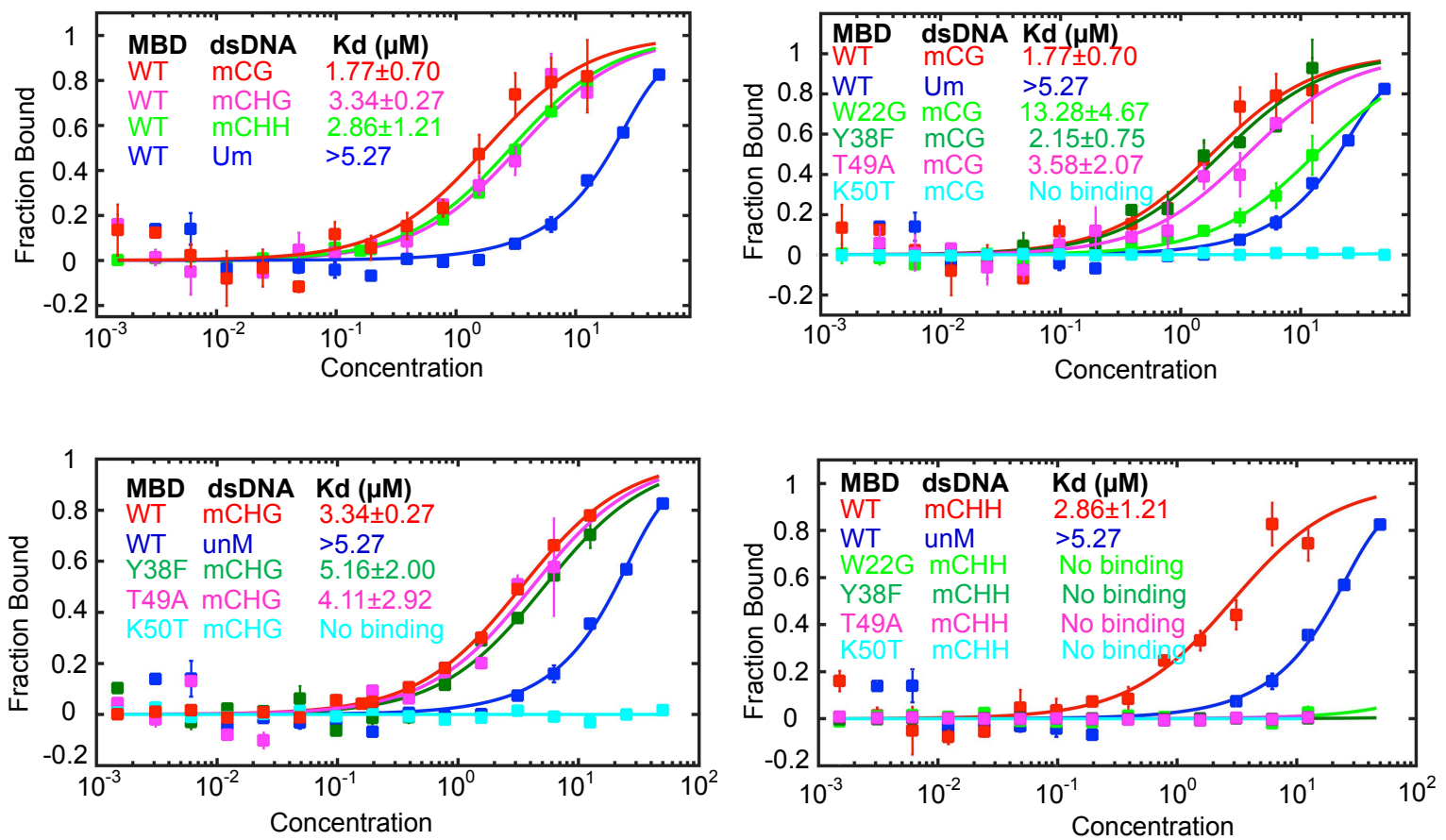

AT5G39160 Um probe $\mathrm{F}$ TTTGGTACGGACTTTTAGTTACAAGAGAGCATTTAAACAAAAATGACCGGTAGATGGAA AT5G39160 Um probe $R$ TTCCATCTACCGGTCATTTTTGTTTAAATGCTCTCTTGTAACTAAAAGTCCGTACCAAA

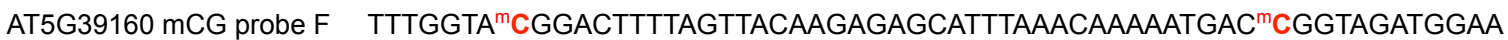

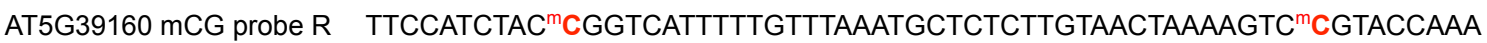

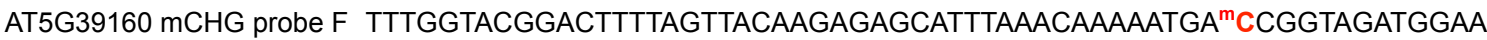

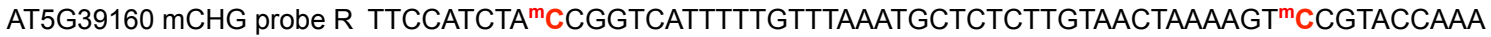
AT5G39160 $\mathrm{mCHH}$ probe $\mathrm{F}$ TTTGGTACGGA ${ }^{\mathrm{m}} \mathrm{CTTTTAGTTA}^{\mathrm{m}} \mathrm{CAAAAGAG}^{\mathrm{m}} \mathrm{CATTTAAA}^{\mathrm{m}}{ }^{\mathrm{C}} \mathrm{CAAAAATGACCGGTAGATGGAA}$ AT5G39160 $\mathrm{mCHH}$ probe R TTCCATCTACCGGTCATTTTTGTTTAAATGCTCTCTTGTAACTAAAAGTCCGTACCAAA 


\section{Figure 5}

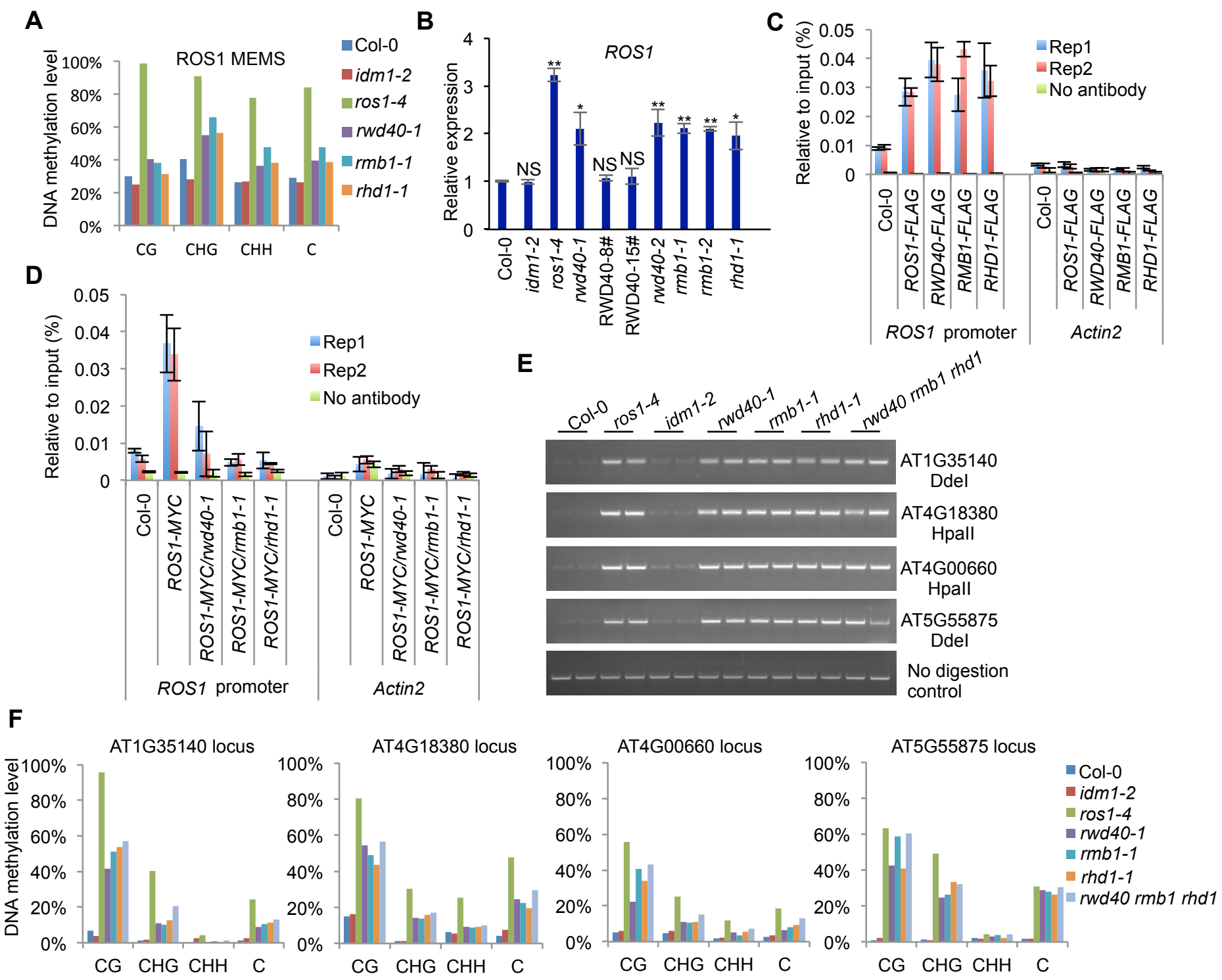




\section{Figure 6}

A

\begin{tabular}{|c|c|c|}
\hline & $\begin{array}{c}\text { up-regulated } \\
\text { genes }\end{array}$ & $\begin{array}{c}\text { down-regulated } \\
\text { genes }\end{array}$ \\
\hline rwd40 rmb1 rhd1 & 3,817 & 4,028 \\
\hline ros1-4 & 2,970 & 2,918 \\
\hline
\end{tabular}

B

Up-regulated DEGs

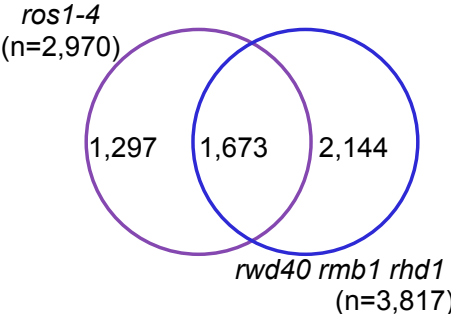

D

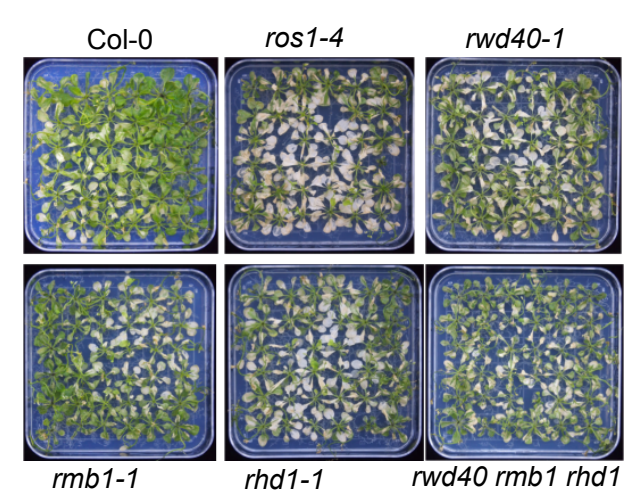

E
C
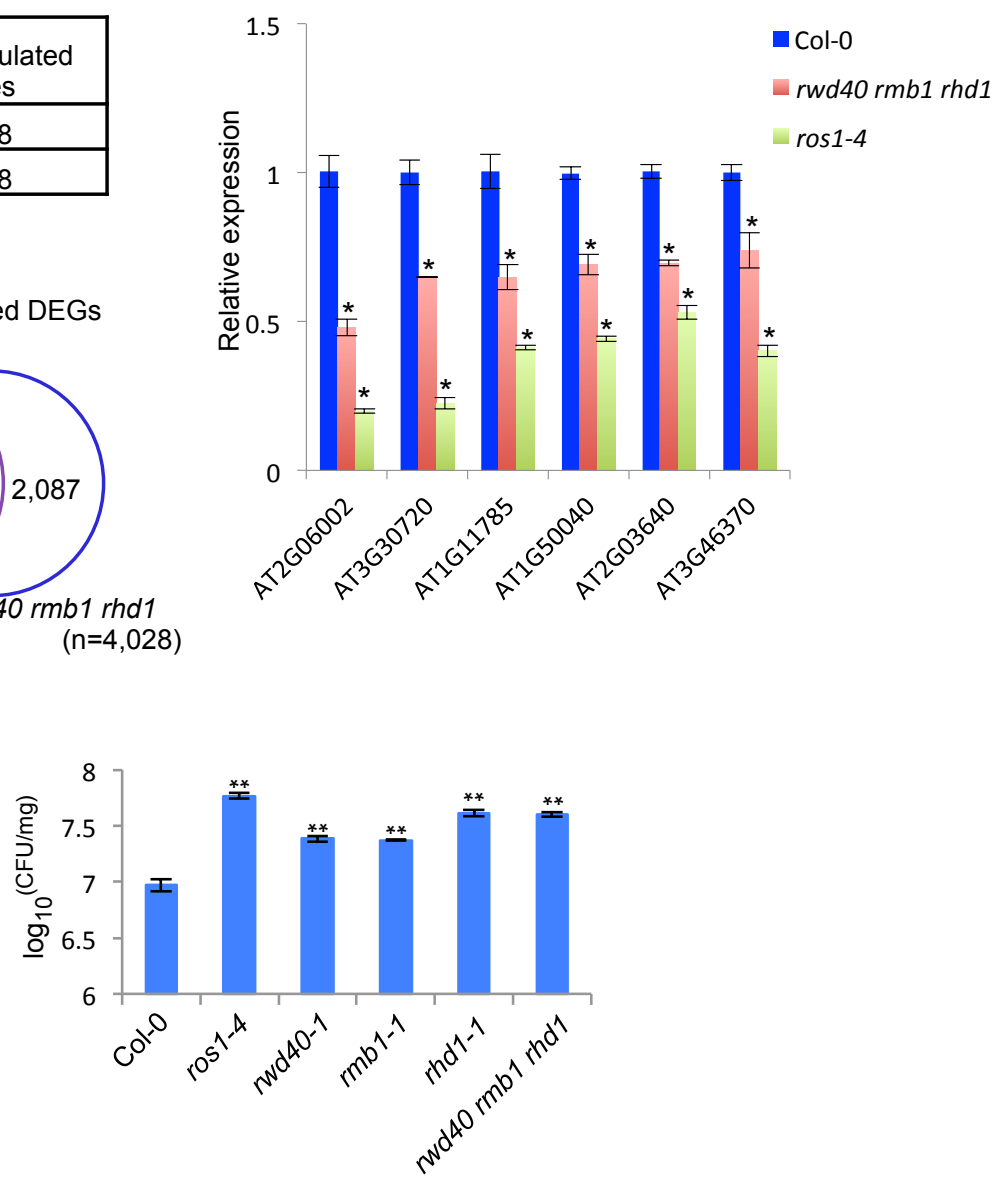
Figure 7

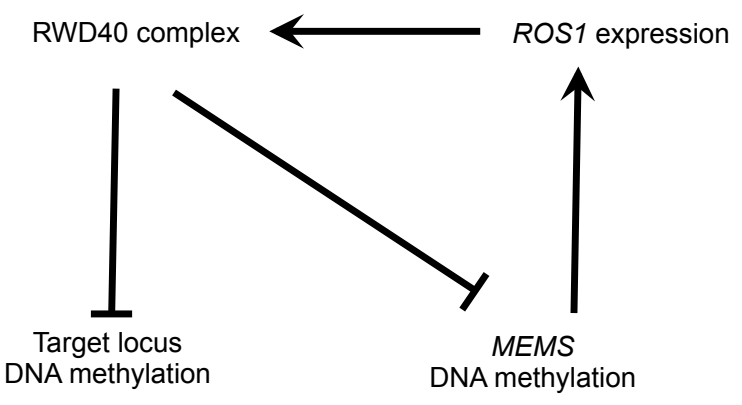




\section{Figure S1}

A

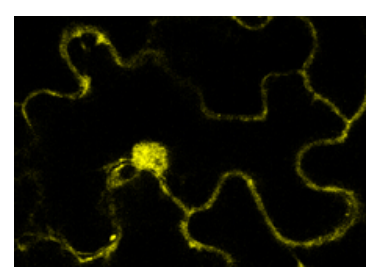

pDEX::RWD40-YFP

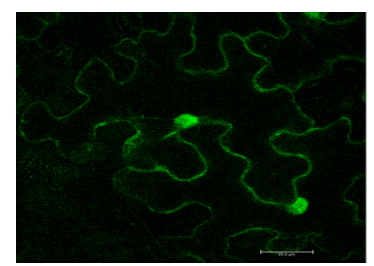

35S::GFP:RWD40

B

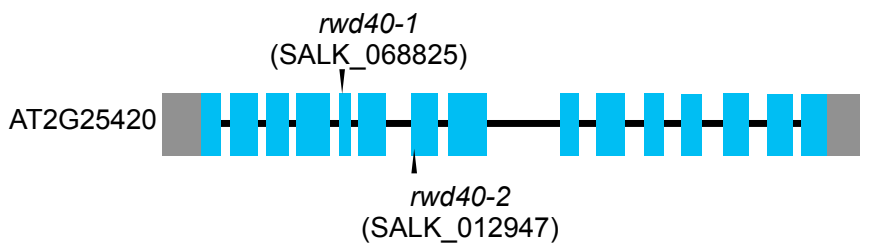

C

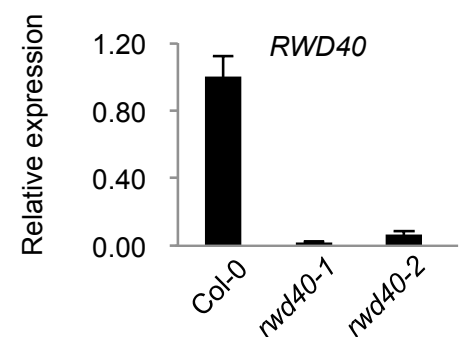

F

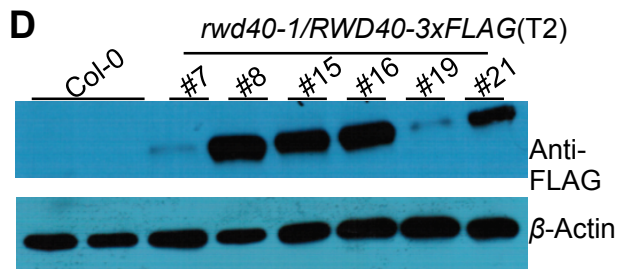

E
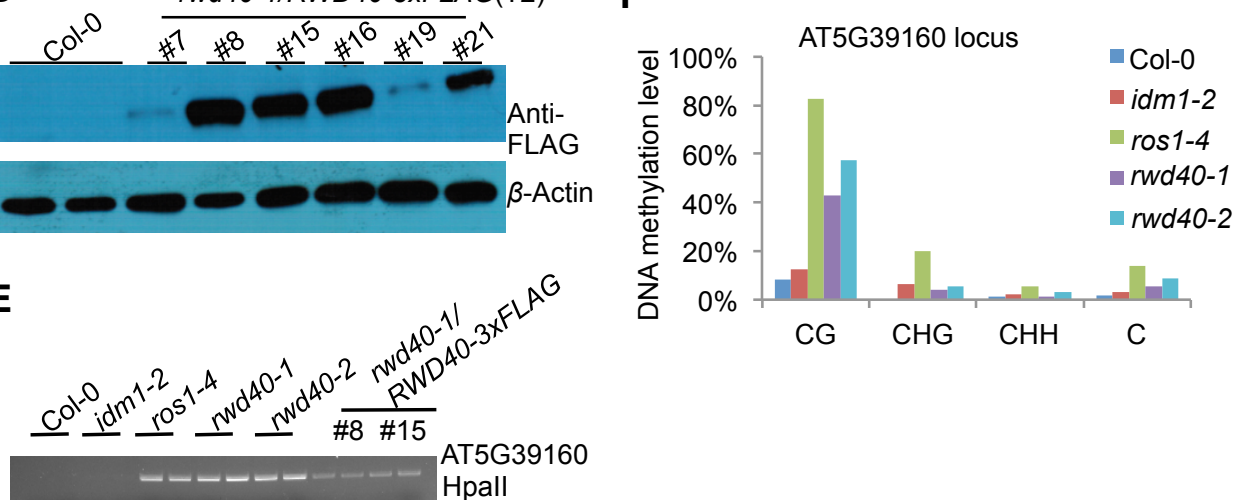

Hpall 


\section{Figure S2}

A

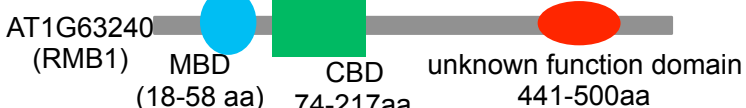
rmb1-1

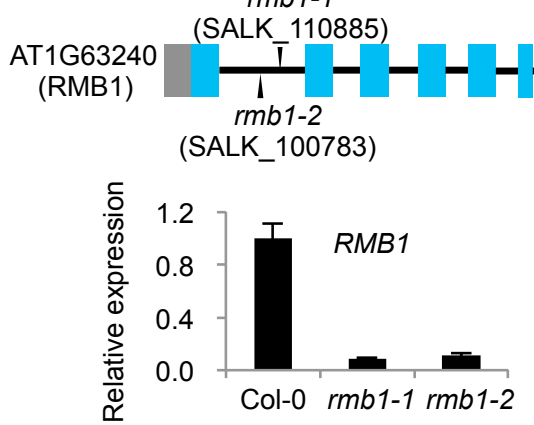

C

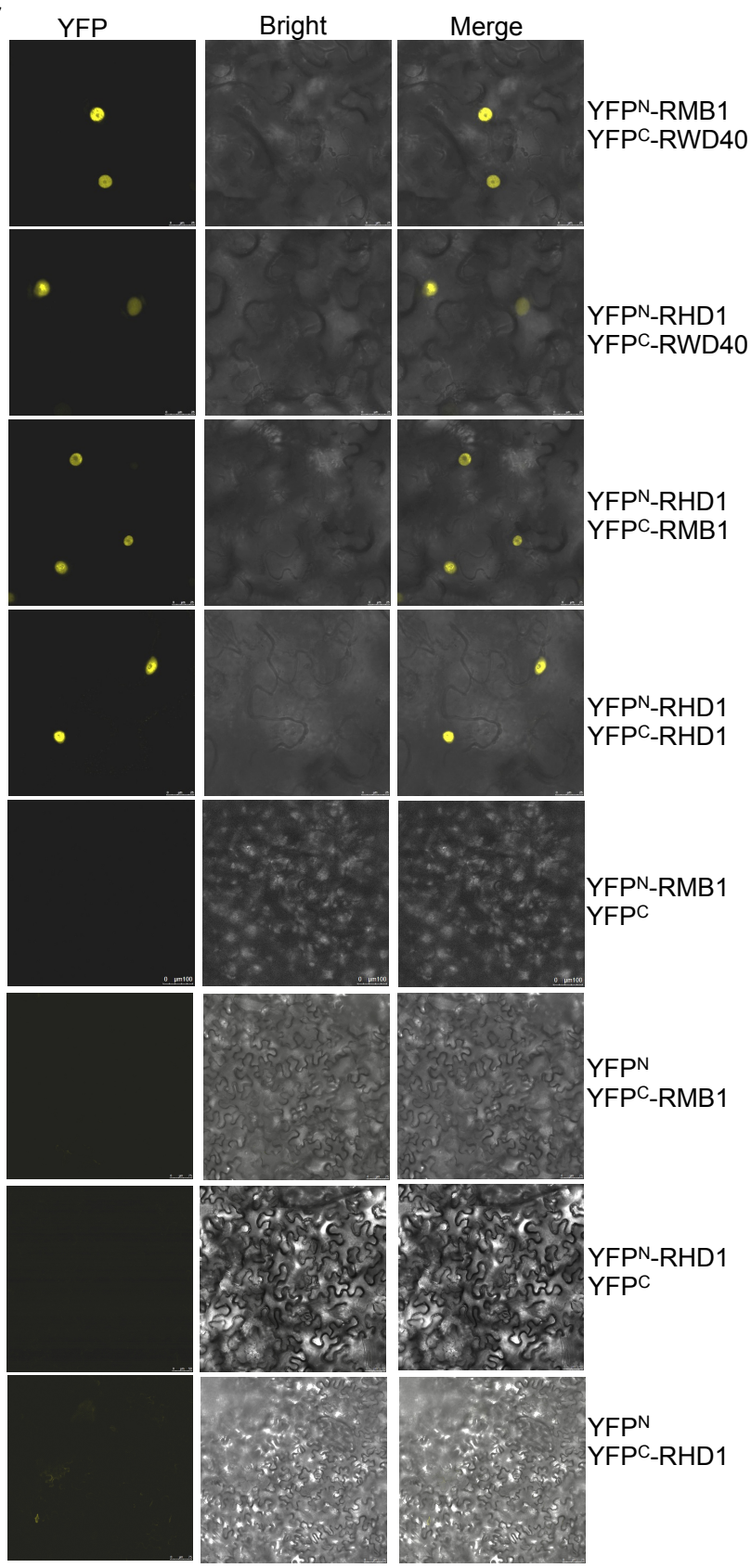

B

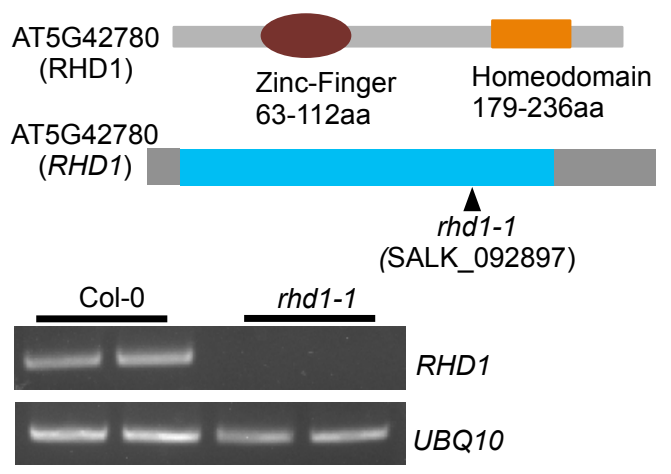

D

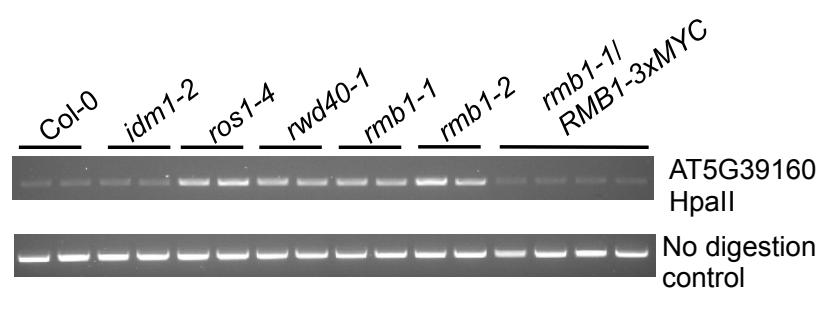

E

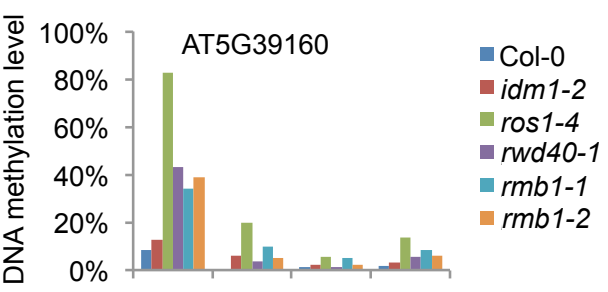

$F$
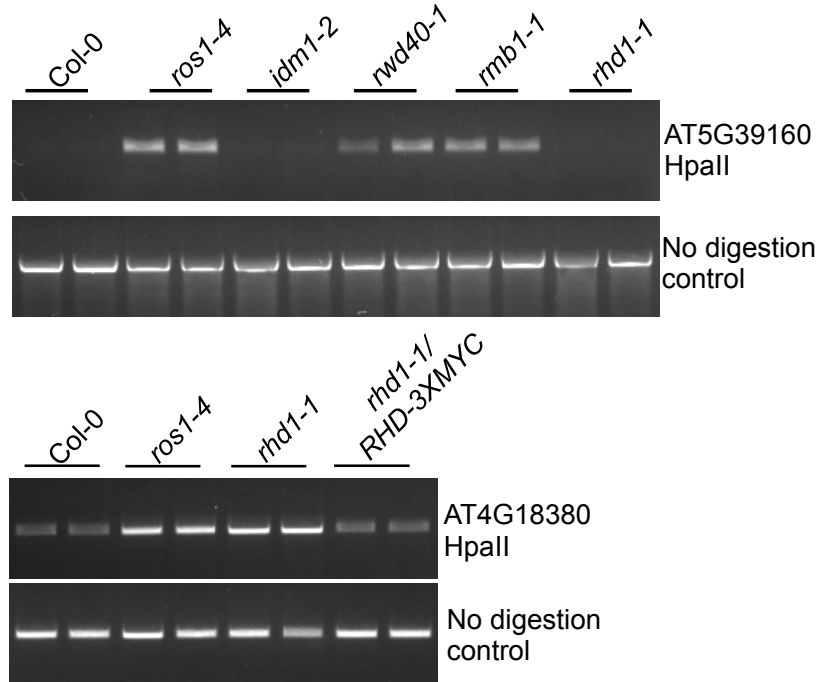


\section{Figure S3}

A

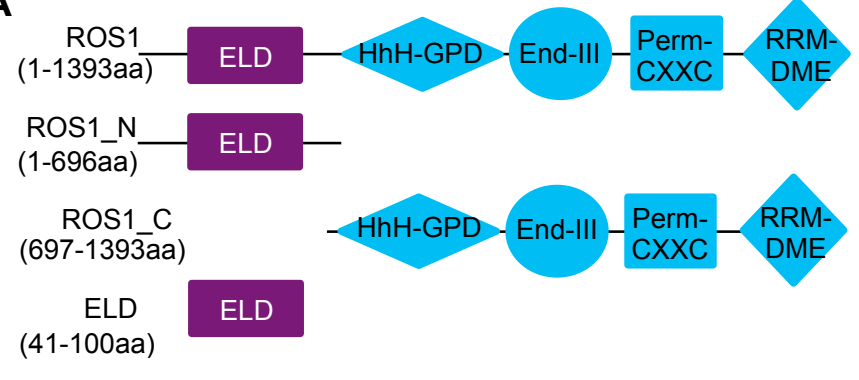

$+1+3+5$

4-DNGLELSLGLSS-15 EAR Motif

ROS1 (50-65aa) :50-GNKDMSGLDHLSFGDLL-65 NINJA (4-15aa):4 -DN - - - -GLE -LSLG -LSS-15

\section{B}

$$
\begin{array}{r}
\text { BD/AD } \\
\text { ROS1/RWD40_LI-CT-1st } \\
\text { ROS1/RWD40_2LI-CT } \\
\text { ROS1_N/RWD40 } \\
\text { ROS1_ELD/RWD40 } \\
\text { ROS1/RWD40_WD40 } \\
\text { ROS1_C/RWD40 } \\
\text { ROS1/Vec } \\
\text { ROS1_N/Vec } \\
\text { ROS1_ELD/Vec } \\
\text { ROS1_C/Vec } \\
\text { Vec/RWD40 } \\
\text { Vec/RWD40_LI-CT-1st } \\
\text { Vec/RWD40_WD40 } \\
\text { Vec/Vec }
\end{array}
$$

\begin{tabular}{|c|c|c|}
\hline \multirow{2}{*}{$\frac{\mathrm{BD} / \mathrm{AD}}{\mathrm{RHD} 1 / \mathrm{RHD} 1 \_\mathrm{P} 1} \mathrm{LT}$} & LTH+3AT & LTHA+3AT \\
\hline & & \\
\hline RHD1/RHD1_P2 OO & $0+$ & 89 \\
\hline RHD1/RHD1_P3 O & 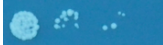 & $6 \%$ \\
\hline RHD1/RHD1_P4OO & 施 & (92) \\
\hline RHD1/RHD1_P5 00 & & \\
\hline RHD1_P3/RHD1 0 & Os... & 厤 \\
\hline RWD40/RHD1_P1 & & \\
\hline RWD40/RHD1_P2 & $0 \times$ & 58 \\
\hline RWD40/RHD1_P3 & & \\
\hline RWD40/RHD1_P4 & & \\
\hline RWD40/RHD1_P5 0 앙 & & \\
\hline $\begin{array}{r}\text { RWD40_WD40 } \\
\text { /RHD1_P2 }\end{array}$ & 0 & $8 \%$ \\
\hline Vec/RHD1_P1OO & & \\
\hline Vec/RHD1_P2 O & & \\
\hline Vec/RHD1_P3 O is of & & \\
\hline Vec/RHD1_P4OO & & \\
\hline Vec/RHD1_P5 O & & \\
\hline RWD40/Vec 000 & 0 & \\
\hline
\end{tabular}

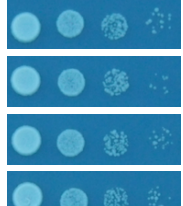

LTH+3AT

LTHA+3AT
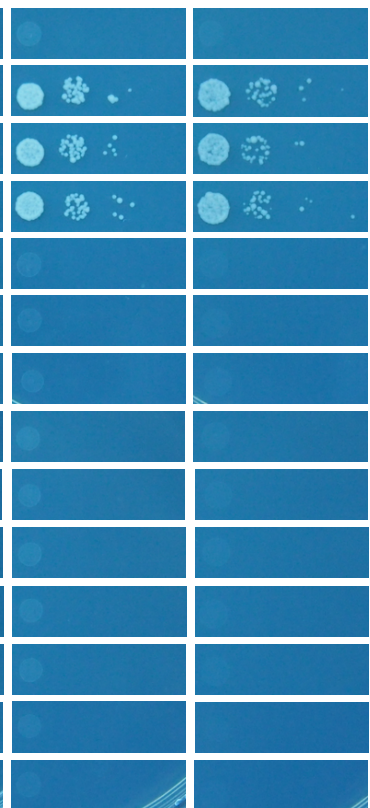

E

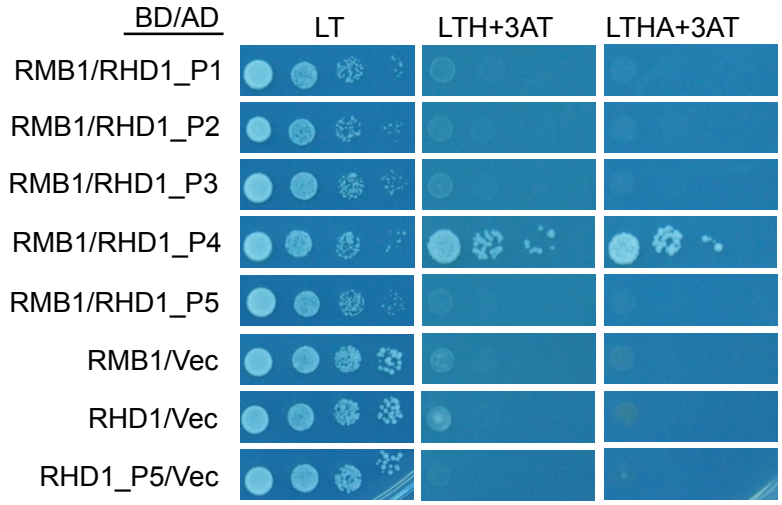

C

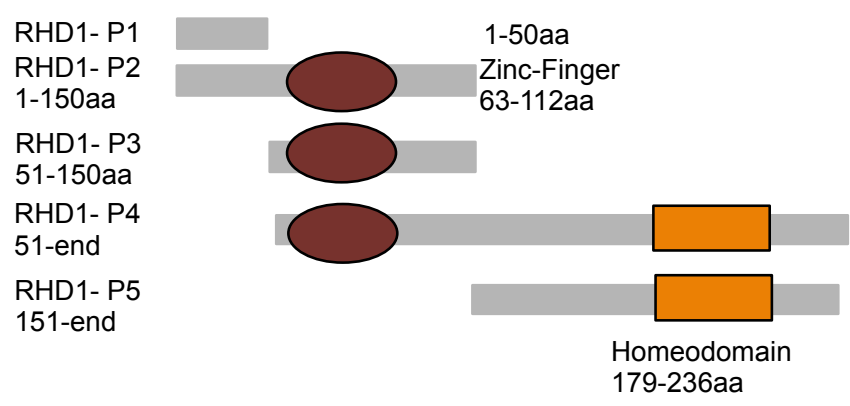

D 


\section{Figure S4}

A

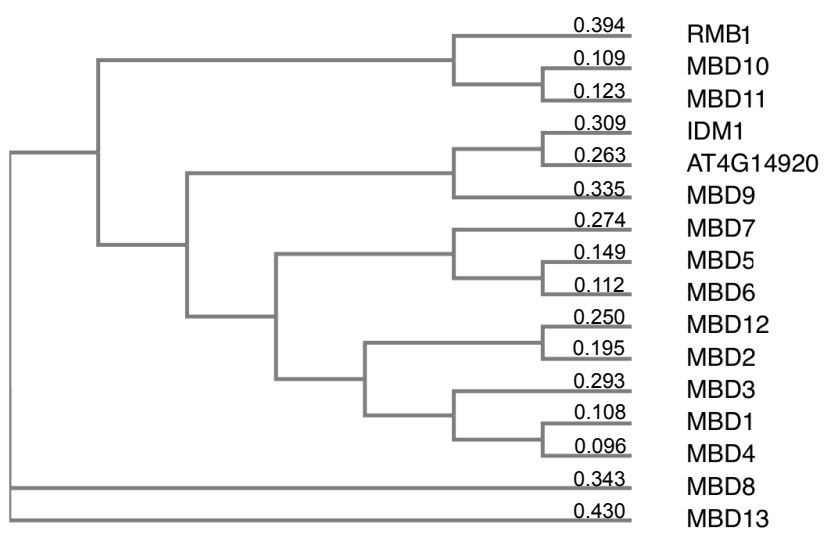

B

RMB1

MBD10

MBD11

MBD3

MBD1

MBD4

IDM1

MBD7

MBD5

MBD 6

MBD13

MBD8

MBD12

MBD2

MBD 9

AT4G14920

consensus $>50$
VVGIAHSTVLKRGROTRT. Y YTOTRTGKKTSTKDOVLEYIKMEK...

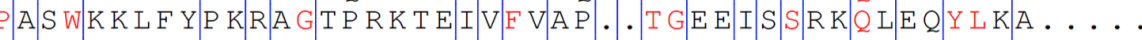
SSWKKLFYPNKVGSVKKTEVVEVAP. . T GEEISNRKQLEQYLKS ..... P Q G L K R L VVR T N CVKVDVYYES LAP. . RRKRFKSIKEVIATE I E REE .

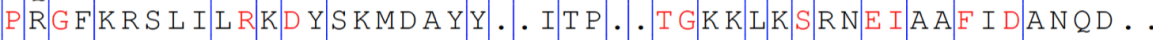

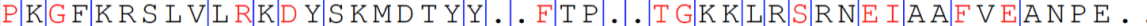
LTA ARWK I ERRER S A R K H VDTF Y SP. EGRKFREFGSAWKA L G G I L A D

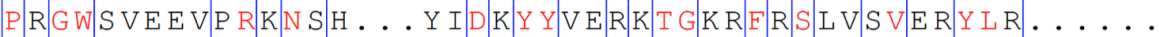

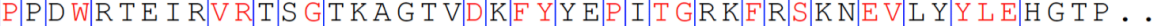

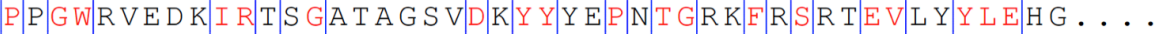
P E GW I KK L E I T N R S GRK T R R D P F F I D P K S E Y I F P R GWR LMLYIKRK GS N L L A CRR Y I P. D GQQFETCKEVISTYLR .....

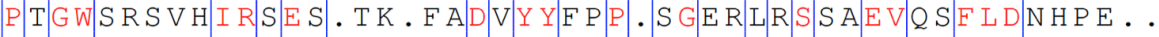
P A GWORLLR IRG EGGTR. F ADVYYVAP. SGKKLR S TVIEVOKYNDNSE..

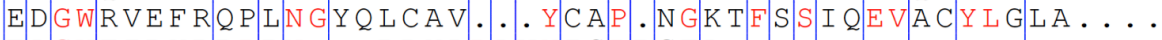

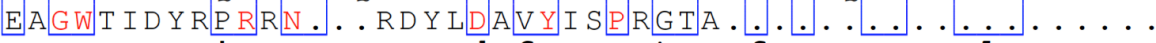
p.gw....ir.ng.....d.fy..p.tg..f.s..ev..yle..... 


\section{Figure S5}

A

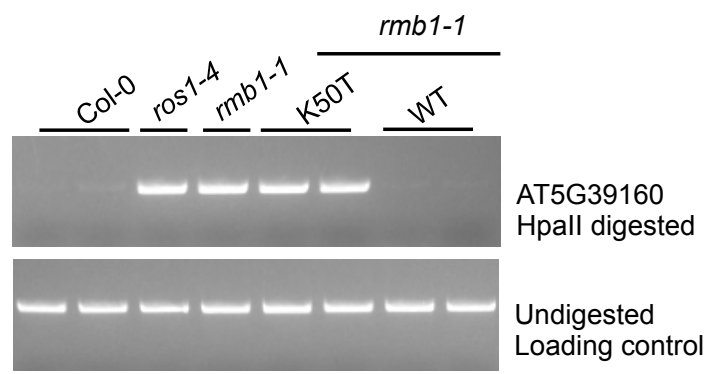

B

AT5G39160 locus

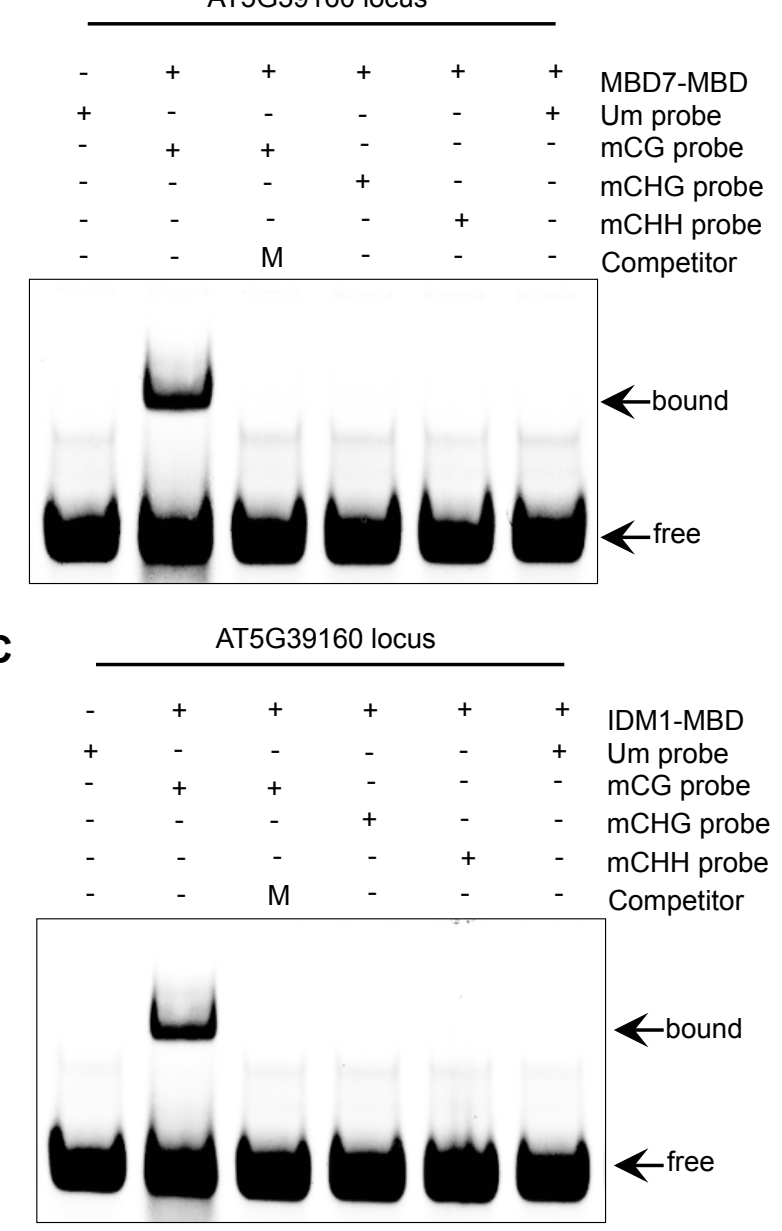


Figure S6

A

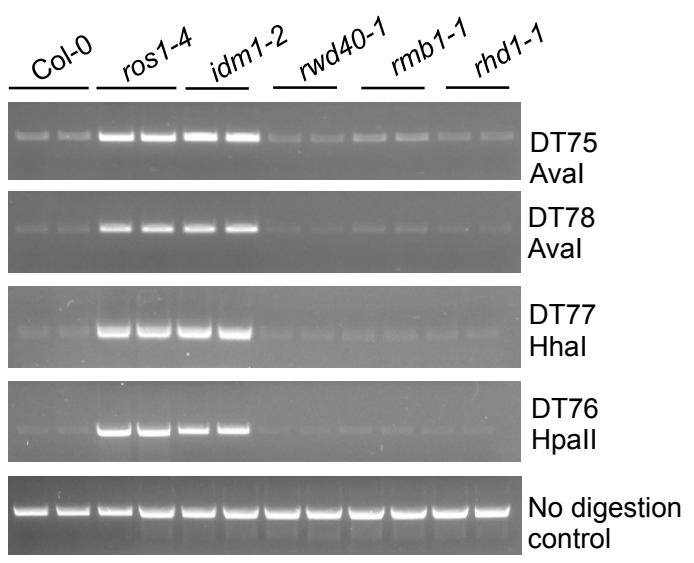

B

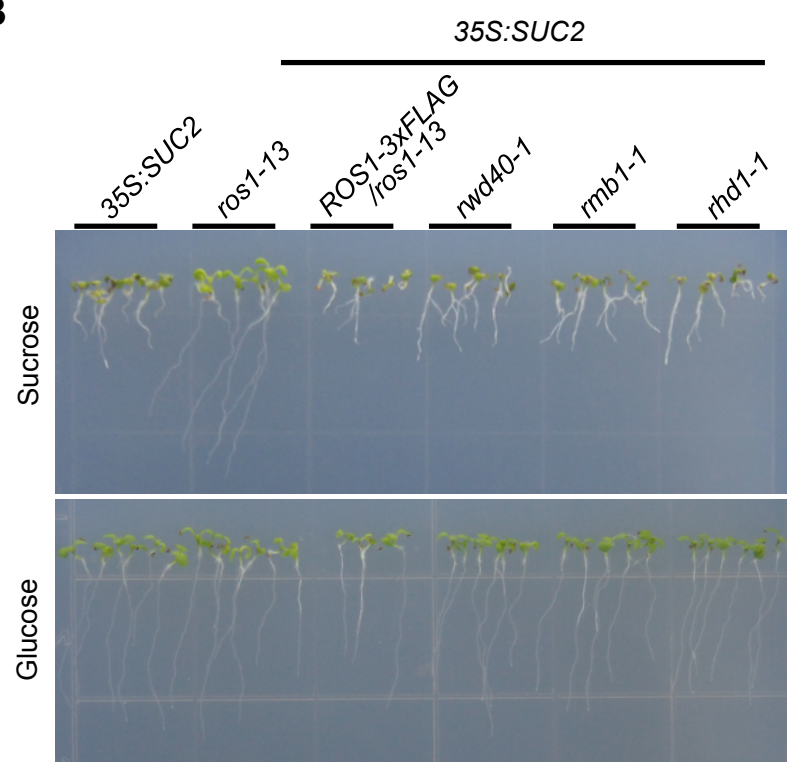

C

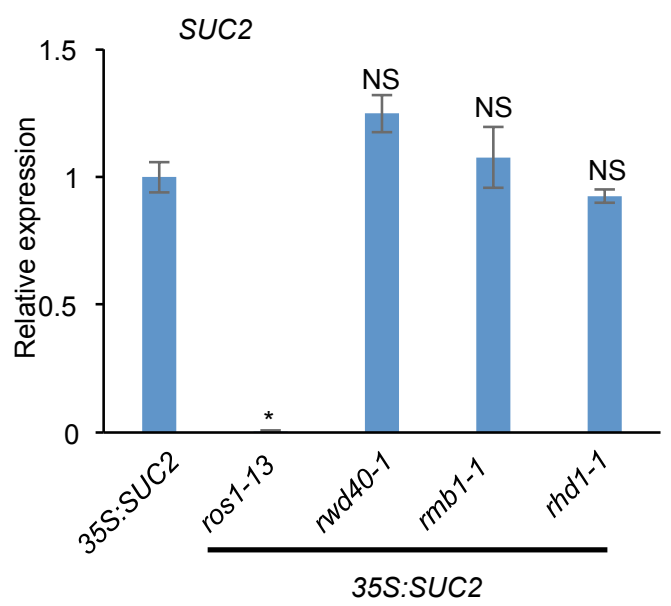

D
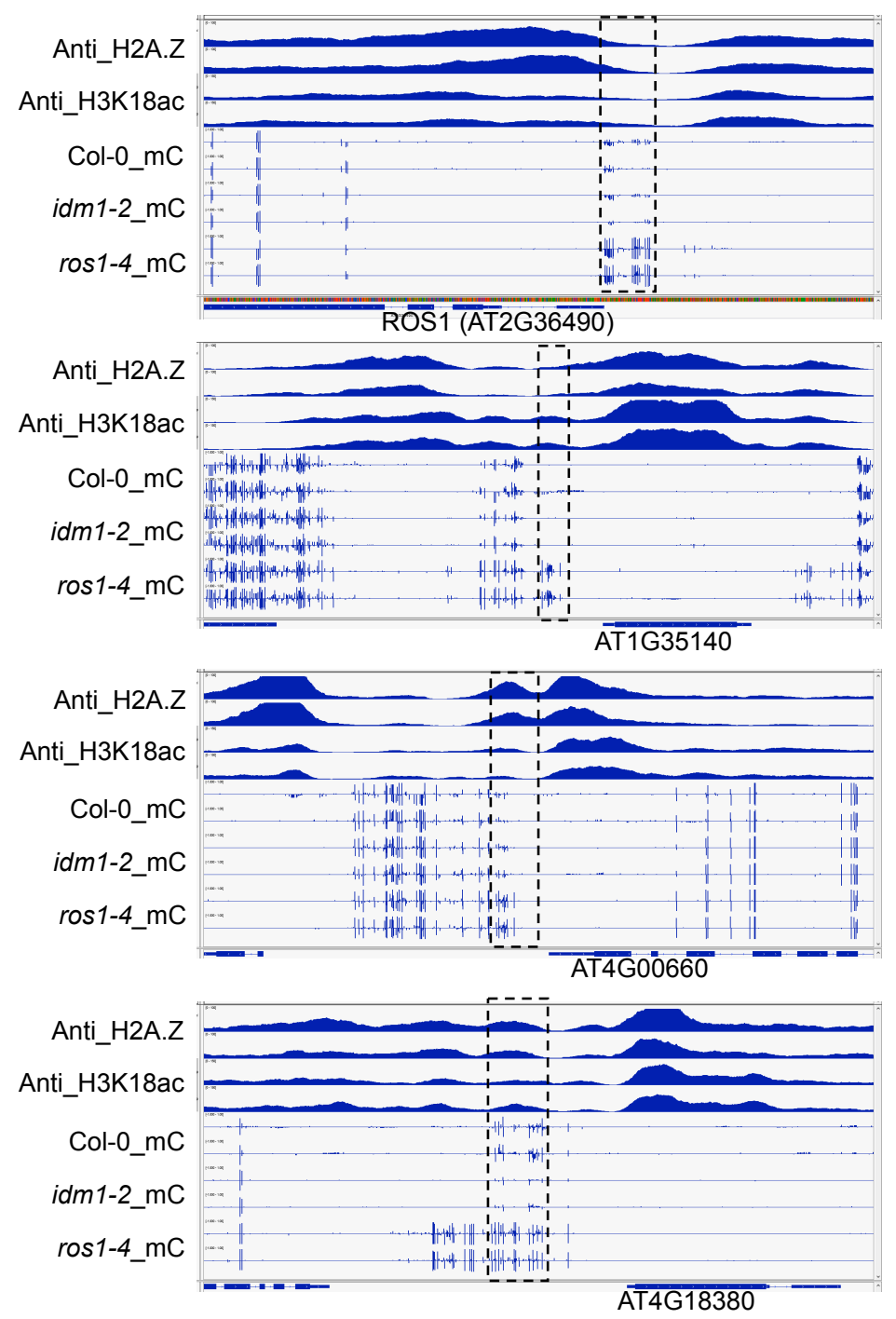

Anti_H2A.Z

Anti_H3K18ac

Col-0_mC

idm1-2_mC

ros 1-4_mC

IInt

int

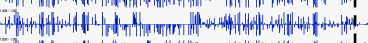

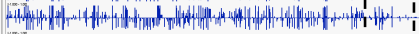

matity

AT5G55875

Anti_H2A.Z

Anti_H3K18ac

Col-0_mC

idm1-2_mC

ros1-4_mC

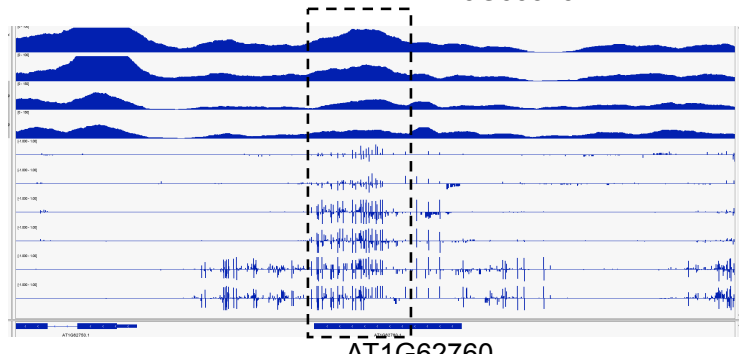


Figure S7 Full-size images of $\mathrm{Y} 2 \mathrm{H}$ shown in this study

\section{Figure 1B}
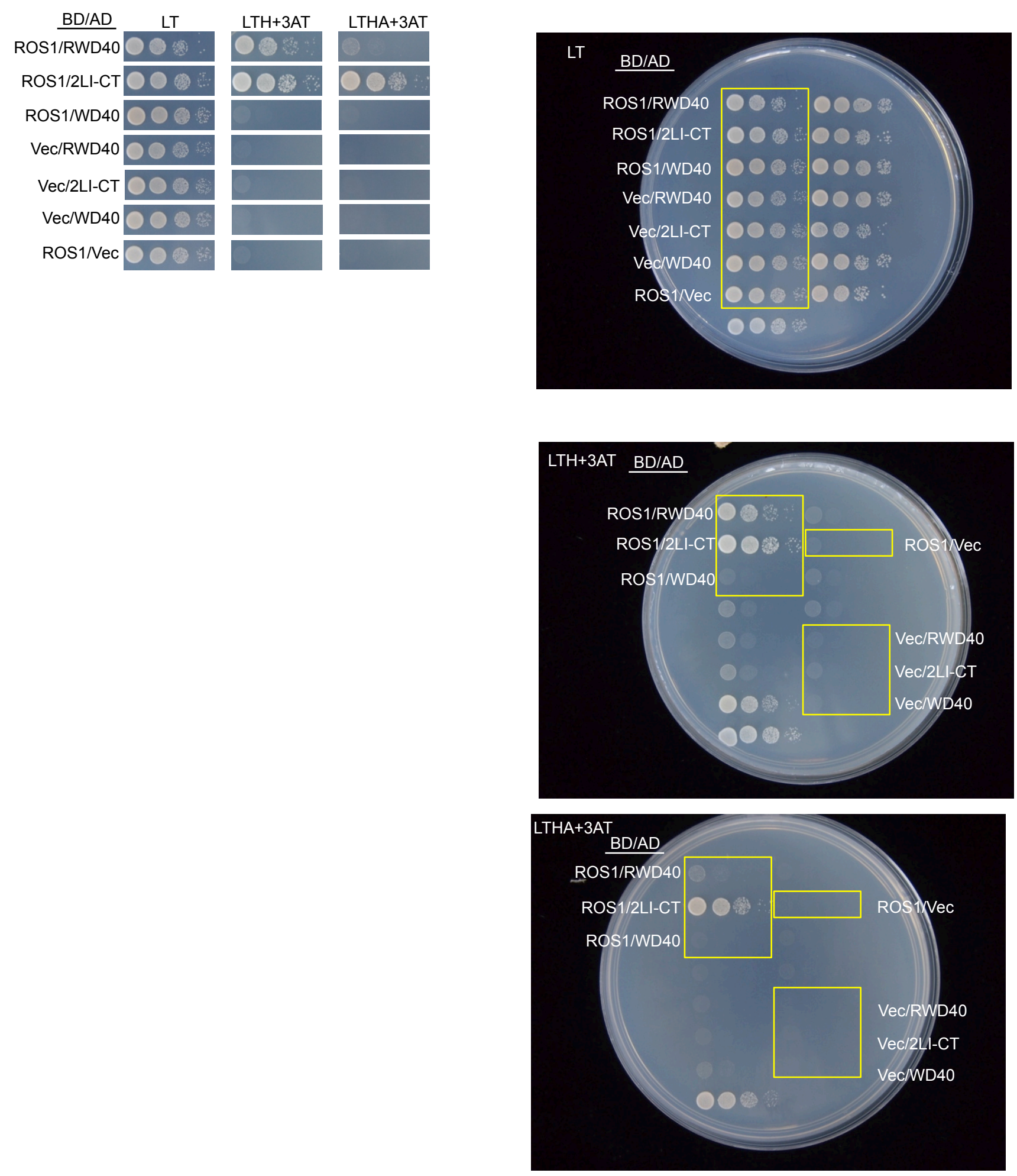


\section{Figure S7 Continued}

Figure 2A

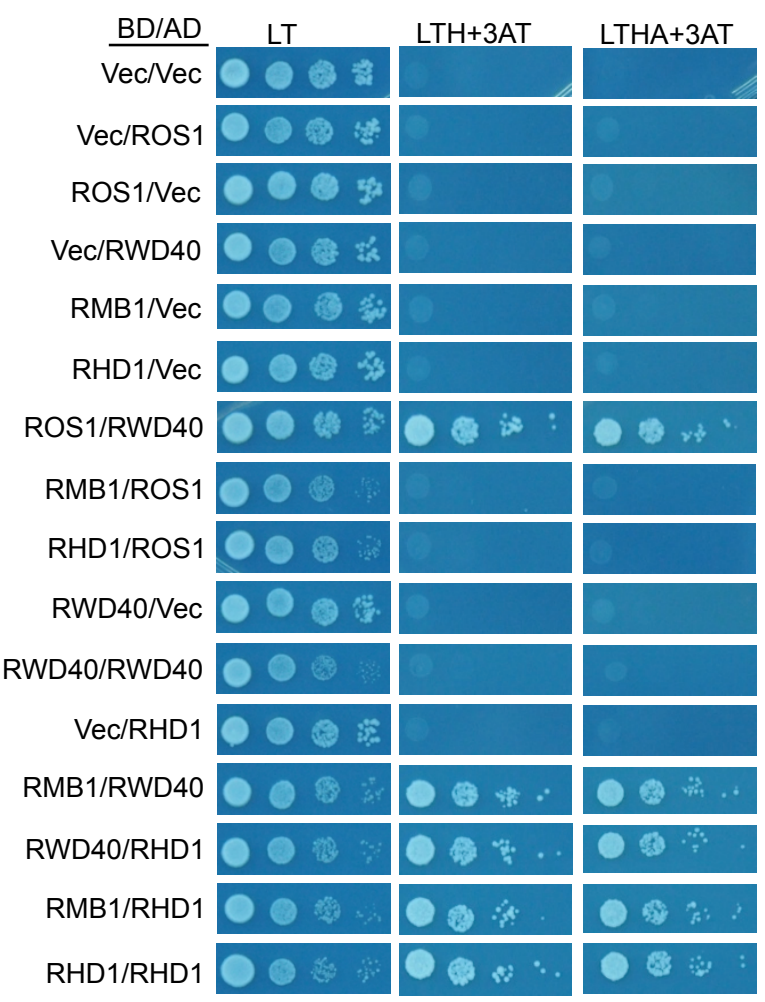

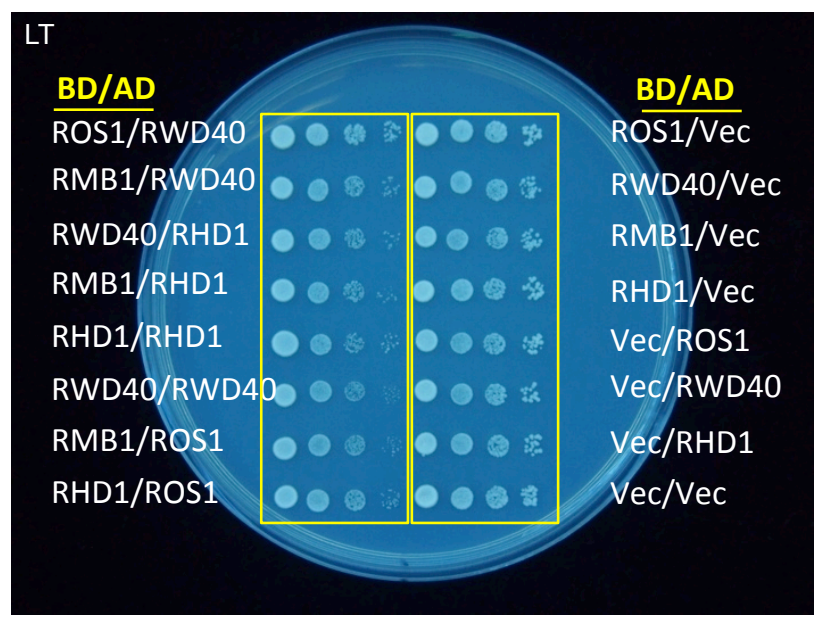
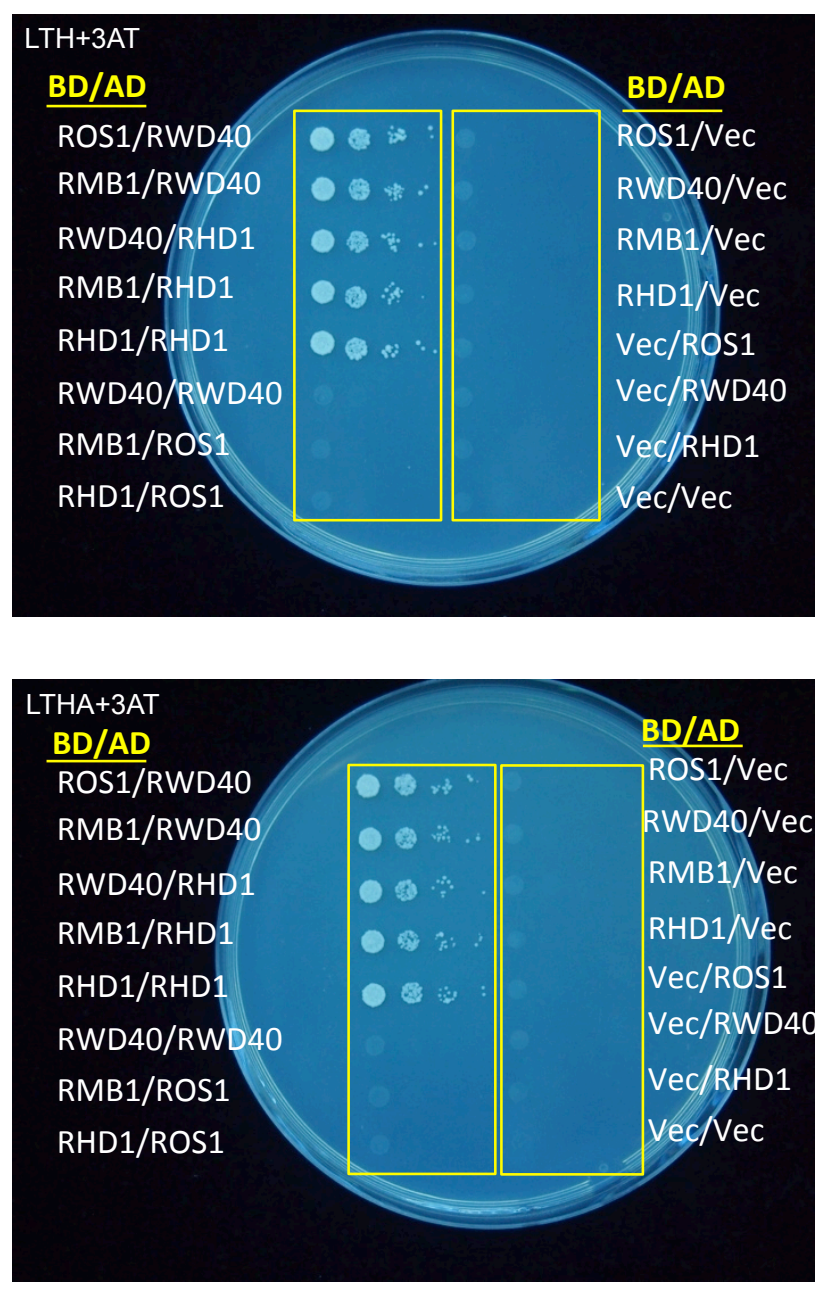


\section{Figure S7 Continued}

\section{Figure 2D}

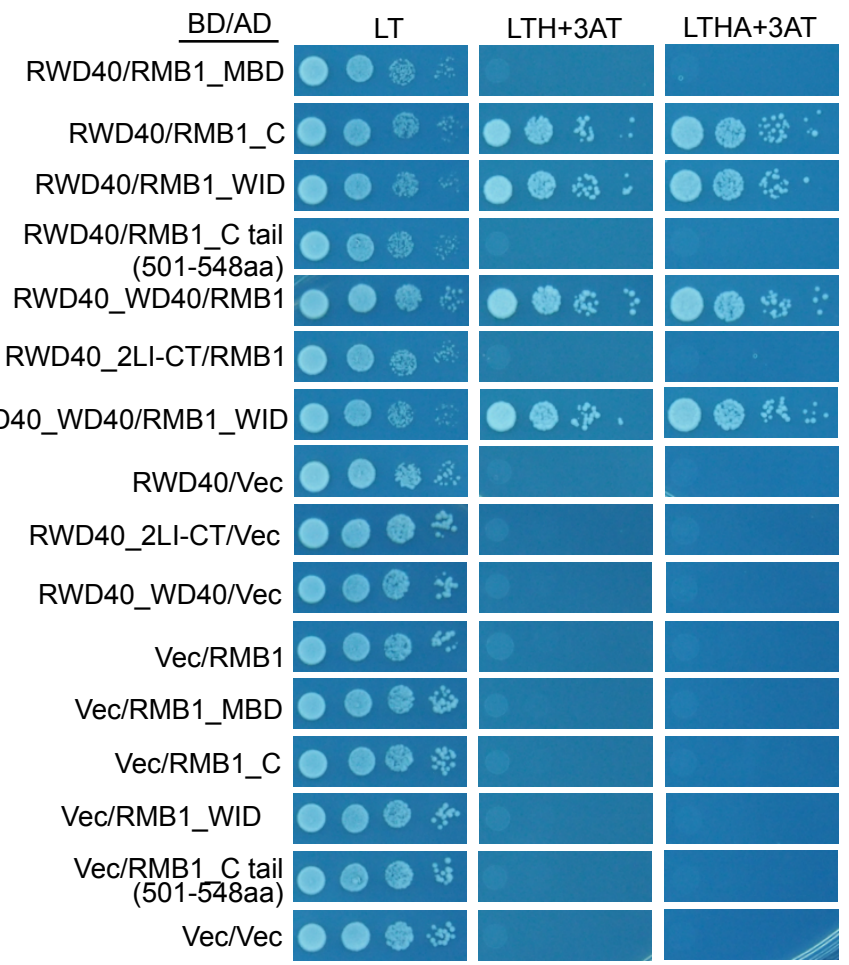

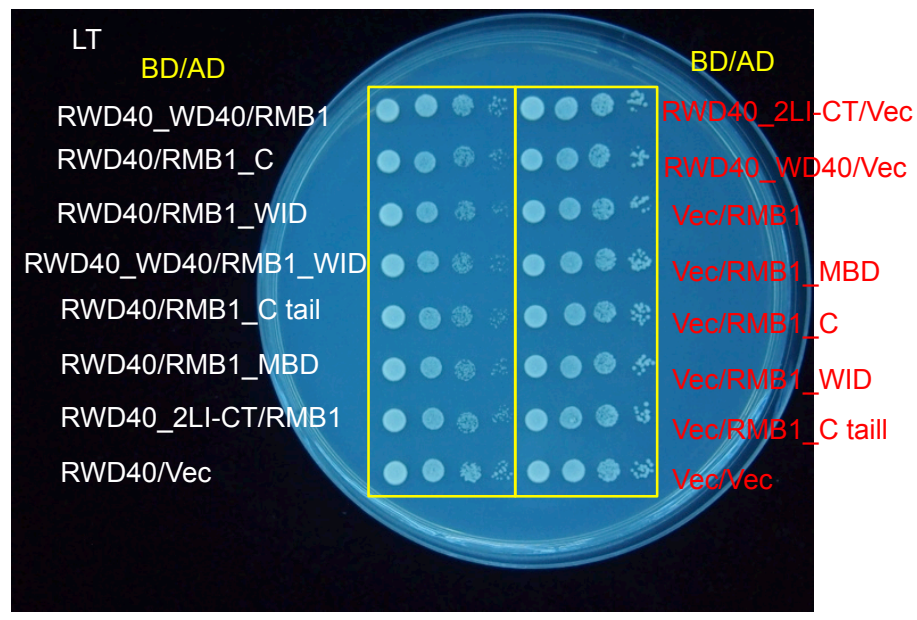
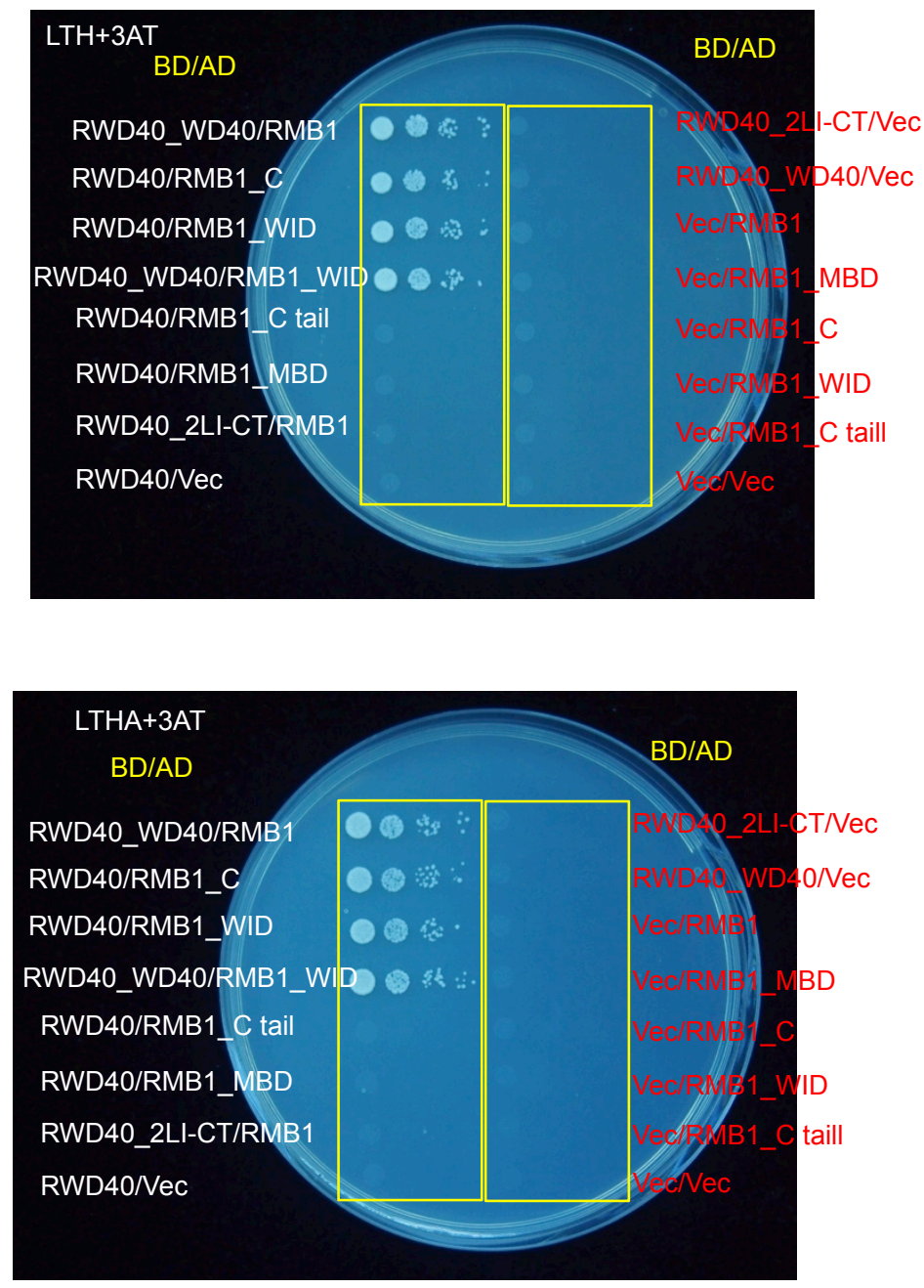


\section{Figure S7 Continued}

\section{Figure S3B}

\begin{tabular}{|c|c|c|c|}
\hline $\mathrm{BD} / \mathrm{AD}$ & LT & LTH+3AT & LTHA+3AT \\
\hline \multicolumn{4}{|c|}{ ROS1/RWD40_LI-CT-1st } \\
\hline ROS1/RWD40_2LI-CT & 00 & 0 皮. & 0 \\
\hline ROS1_N/RWD40 & 00 & O緮 & $0 \%$ \\
\hline ROS1_ELD/RWD40 & 00 綎: & 0 緯 & 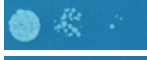 \\
\hline \multicolumn{4}{|l|}{ ROS1/RWD40_WD40 } \\
\hline \multicolumn{4}{|l|}{ ROS1_C/RWD40 } \\
\hline \multicolumn{4}{|l|}{ Ros1/Vec } \\
\hline \multicolumn{4}{|c|}{ ROS1_N/Vec $O O O$} \\
\hline \multicolumn{4}{|c|}{ ROS1_ELD/Vec OO } \\
\hline \multicolumn{4}{|c|}{ ROS1_c/Vec OO is } \\
\hline \multicolumn{4}{|c|}{ Vec/RWD40 00 is } \\
\hline \multicolumn{4}{|c|}{ Vec/RWD40_LI-CT-1st } \\
\hline Vec/RWD40_WD40 & 000 尔 & & \\
\hline $\mathrm{Vec} / \mathrm{Vec}$ & 000 है। & & \\
\hline
\end{tabular}
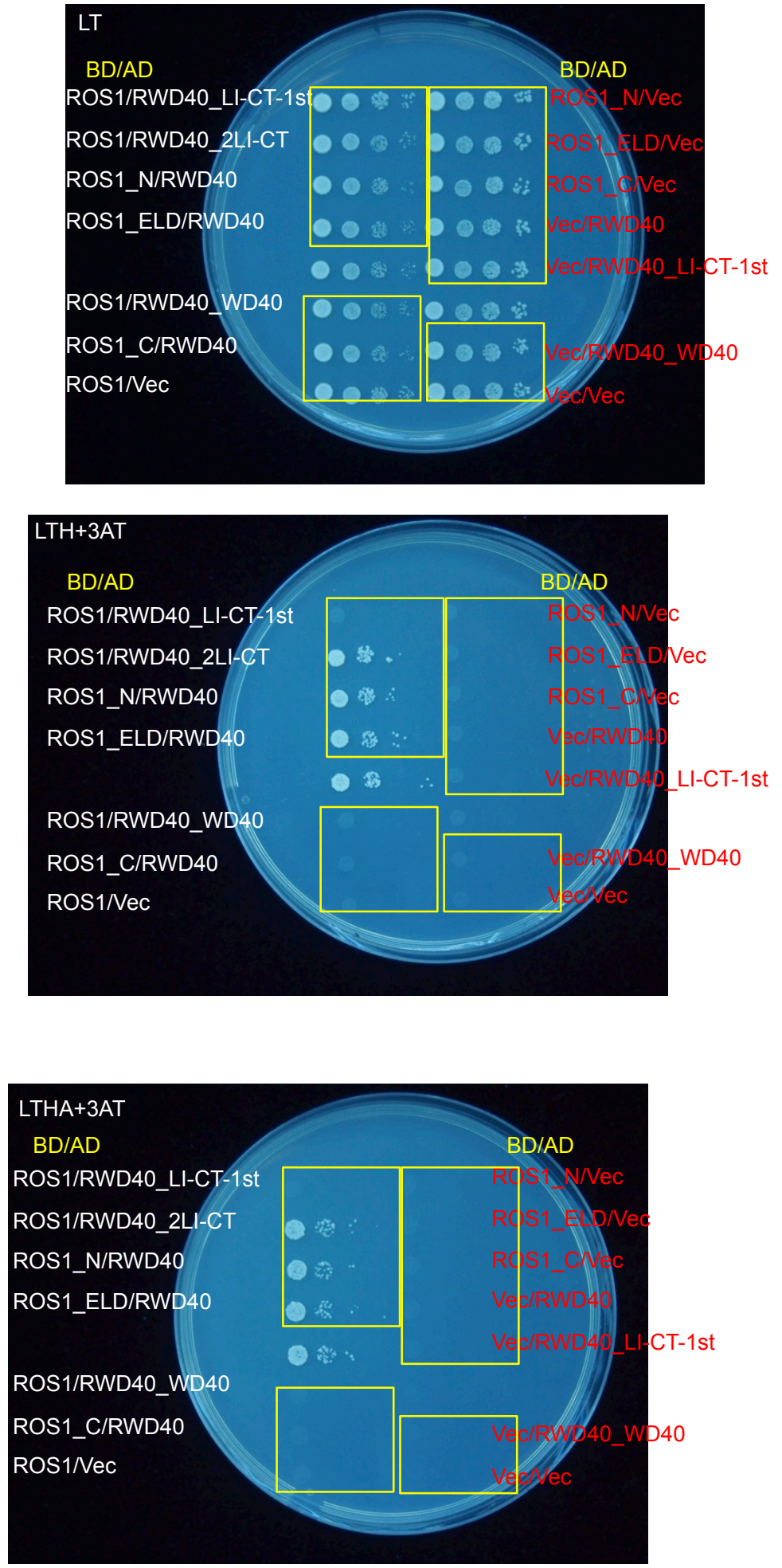
Figure S7 Continued

\section{Figure S3D}
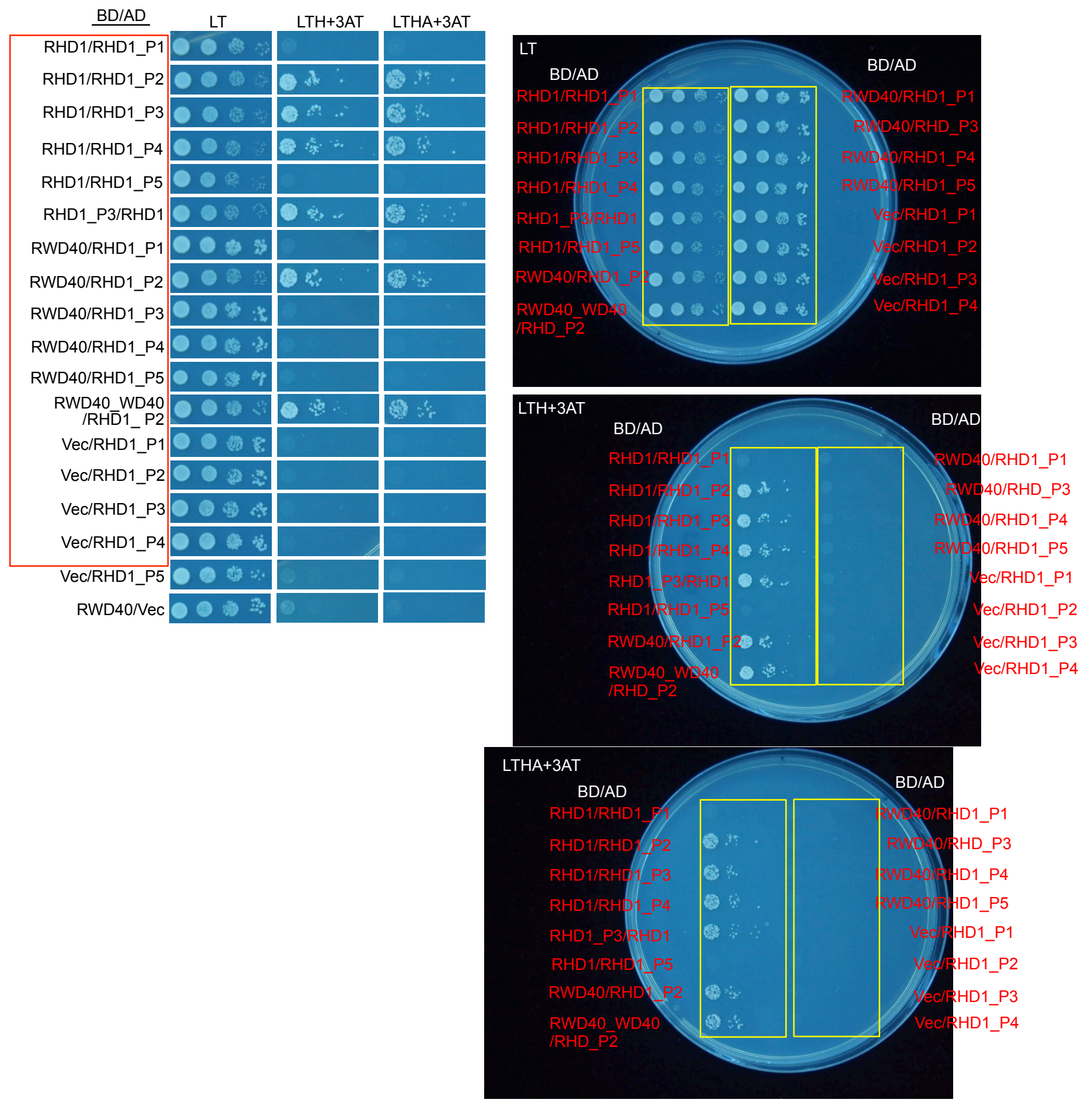
Figure S7 Continued

Figure S3D

\begin{tabular}{|c|c|c|}
\hline$B D / A D$ & LTH+3AT & LTHA+3AT \\
\hline RHD1/RHD1_P1OO & & \\
\hline RHD1/RHD1_P2 00 & Ca: & $8 \%$ \\
\hline RHD1/RHD1_P3 & Con & $8 \%$ \\
\hline RHD1/RHD1_P4 0 & C & 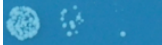 \\
\hline RHD1/RHD1_P5 0 & & \\
\hline RHD1_P3/RHD1 & $0 \%$ & 疑 \\
\hline RWD40/RHD1_P1 & & \\
\hline RWD40/RHD1_P2 & (1) & 3) \\
\hline RWD40/RHD1_P3 $0: x$ & & \\
\hline RWD40/RHD1_P4 $\bigcirc$ & & \\
\hline RWD40/RHD1_P5 0 s of & & \\
\hline $\begin{array}{l}\text { RWD40_WD40 } \\
\text { /RHD1_P2 }\end{array}$ & 0 & 8 \\
\hline Vec/RHD1_P1O & & \\
\hline Vec/RHD1_P2 O & & \\
\hline Vec/RHD1_P3 $\bigcirc$ क की & & \\
\hline Vec/RHD1_P4OO & & \\
\hline Vec/RHD1_P5 & & \\
\hline RWD40/vec $O O$ & & \\
\hline
\end{tabular}
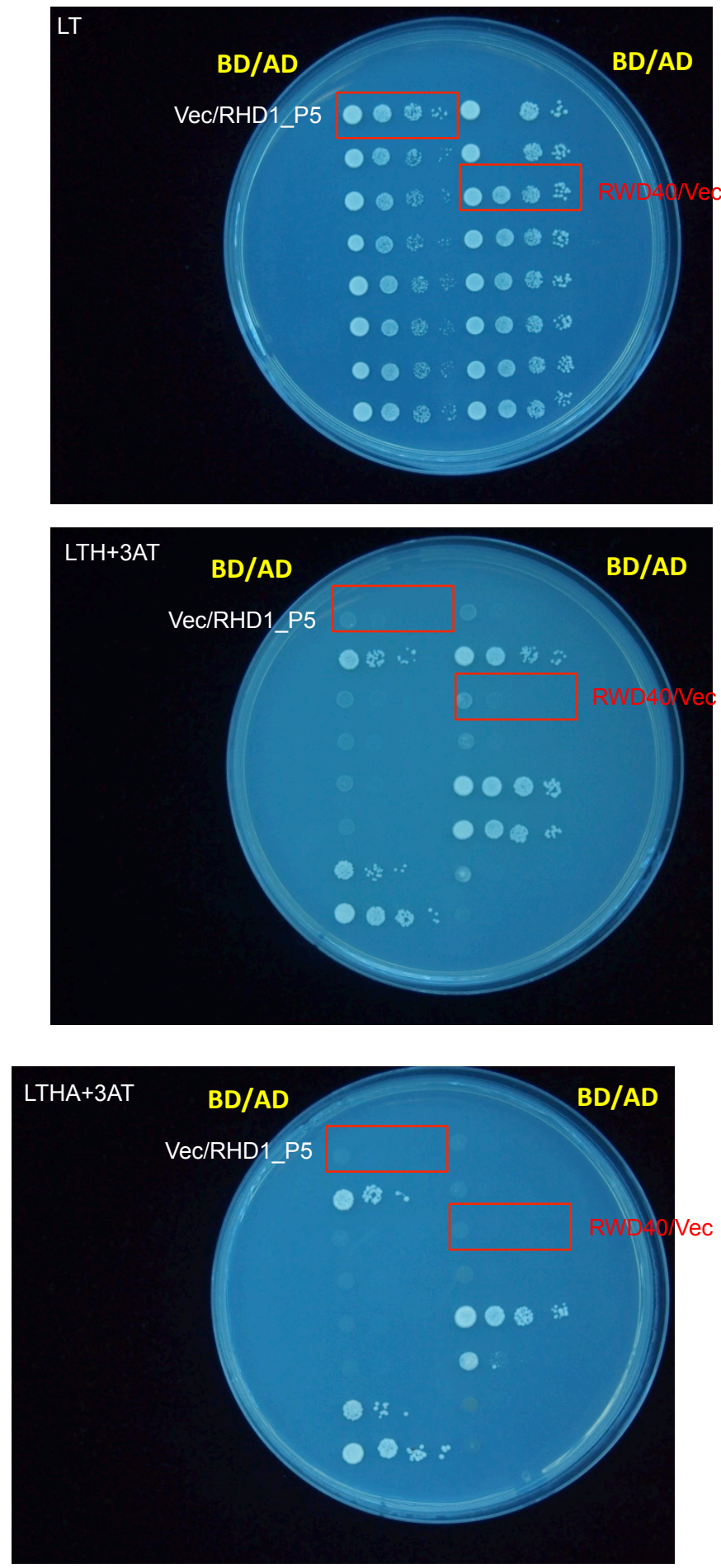
Figure S7 Continued

\section{Figure S3E}

\begin{tabular}{|c|c|c|c|}
\hline$\underline{B D / A D}$ & LT & LTH+3AT & LTHA+3AT \\
\hline RMB1/RHD1_P1 & 00 & & \\
\hline RMB1/RHD1_P2 & 00 & & \\
\hline RMB1/RHD1_P3 & 00 婉 & & \\
\hline RMB1/RHD1_P4 & 00 & O鄚 $\therefore$ & 04 \\
\hline RMB1/RHD1_P5 & 009 & & \\
\hline RMB1/Nec & 00 s & e & \\
\hline RHD1/Vec & $00 \%$ 然 & 0 & \\
\hline RHD1_P5/Vec & 0 항 & & \\
\hline
\end{tabular}
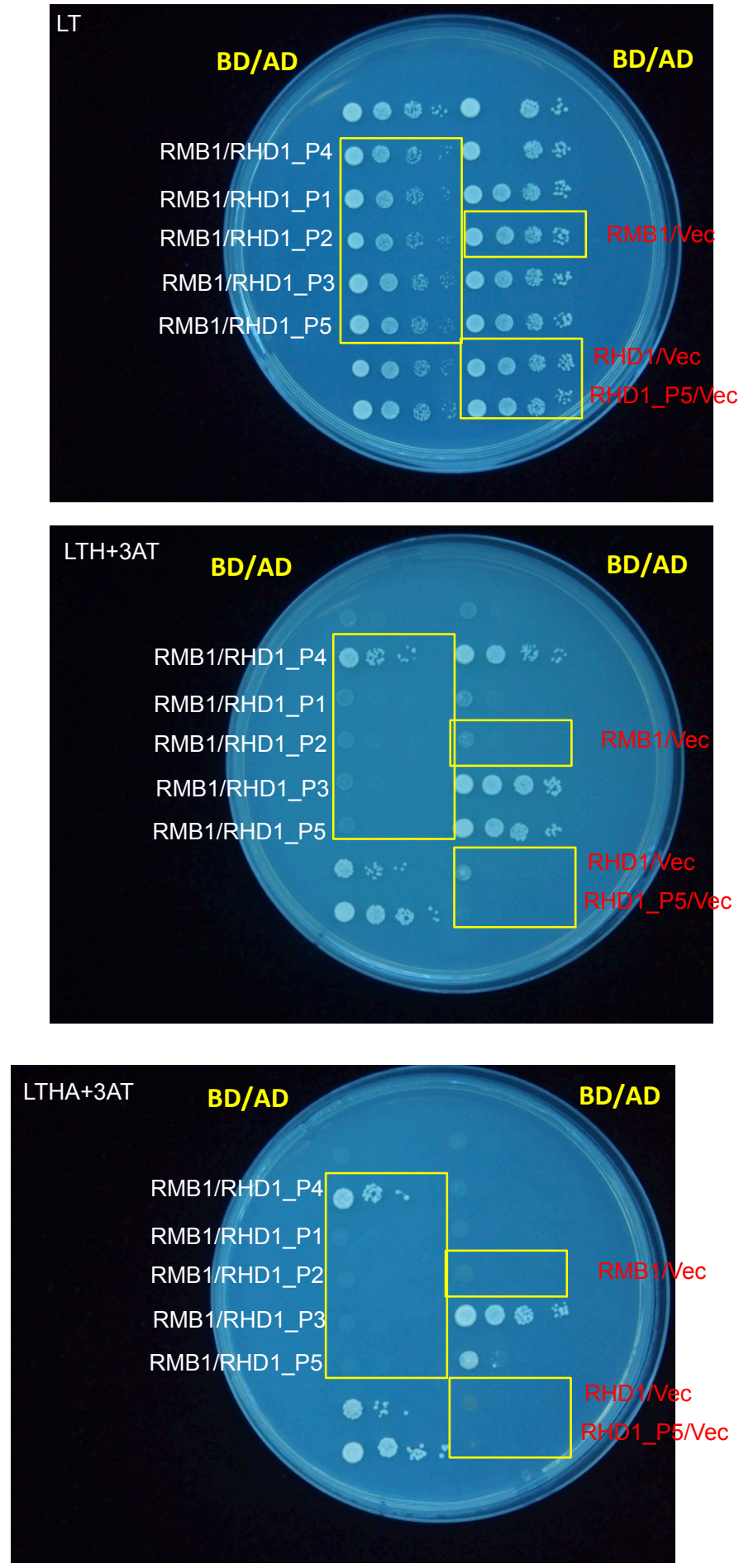